Research Article

\title{
Dynamic Characteristics of Air Cycle Machine Rotor System
}

\author{
Dongjiang Han $(\mathbb{D}$, Long Hao, and Jinfu Yang \\ Institute of Engineering Thermophysics, Chinese Academy of Sciences, 11 Beisihuanxi Road, 100190 Beijing, China \\ Correspondence should be addressed to Dongjiang Han; handongjiang@iet.cn
}

Received 12 April 2018; Revised 3 August 2018; Accepted 26 August 2018; Published 26 September 2018

Academic Editor: Filippo Ubertini

Copyright $(2018$ Dongjiang Han et al. This is an open access article distributed under the Creative Commons Attribution License, which permits unrestricted use, distribution, and reproduction in any medium, provided the original work is properly cited.

Parameters optimization in the critical speed region has the important influence on operational stability of an air cycle machine. Effects of bearing stiffness and unbalanced exciting force on critical speed and response characteristics are investigated by the modal method and harmonic response analysis. Resonance separation phenomenon in the critical speed region is analyzed in detail. When difference exists in the phase of unbalanced exciting force, resonance separation appears in the conical whirling speed region. The characteristics after resonance separation are closely related to the phase difference value and amplitude of unbalanced exciting force. The paper provides theoretical and experimental foundations for resonance separation analysis and also provides data support for dynamic balance and dynamic design of the rotor system.

\section{Introduction}

Airborne pods are used to enhance the tactical performance of the modern aircraft, including EO targeting pod, military intelligence pod, combat navigation pod, infrared distance pod, and military interference pod, e.g., which expand functionality and performance of the carrying aircraft in the field of electronic countermeasure, reconnoiter, navigation, and guidance. Lots of electronic equipment with features of high integration, high accuracy, and large heat flux are in airborne pods. More stringent requirements for environmental control of airborne pods have come up. An independent environmental control system with advantages of high performance, high reliability, light weight, and high power is the prerequisite for keeping the equipment in airborne pods reliably operate [1-5].

Environmental control systems of pods mainly include reverse bootstrap air cycle refrigerating system and steam cycle refrigerating system. The former is simple in structure and has high reliability. Due to ram air with low pressure ability, cooling turbine works in small expansion ratio and enthalpy drop condition, and the refrigerating capacity is limited. Meanwhile, the reverse bootstrap air cycle refrigerating system has no refrigerating capacity on the ground and low control precision in temperature. The latter has advantages of high energy efficiency ratio, temperature control precision, and refrigerating capacity on the ground. But, the steam cycle refrigerating system has some disadvantages of complicated structure, heavy weight, large power, and high maintenance costs [3-5]. Considering active aircrafts in the current situation of power supply tension and poor temperature resistance, it is necessary to develop the reverse bootstrap air cycle refrigerating system.

The core power unit of the reverse bootstrap air cycle refrigerating system is the air cycle machine (ACM). The rotor structure of ACM is the single thrust plate rotor structure of a single-stage radial turbine coaxial with a compressor. Some scholars approached a series of studies on the matching impeller design, optimal design of the bearing, rotor stability control, and machine lightweight in order to enhance refrigerating capacity and power density of ACM. Heshmat et al. discussed bearing design analysis, bearing performance, and system rotor dynamics, including critical speeds and rotor imbalance response during the use of the foil bearing in the aircraft for cabin cooling turbines (ACMs). They presented full rotor bearing development and operational procedures consisting of test results of steady state and random vibrations obtained from both a rotor-bearing simulator and an actual system and showed by tests that advancements made to the foil-bearing technology over the past two decades offer benefits in temperature margins, load carrying capacity, and 
tolerance to debris [6-8]. Xiao et al. [9] carried out the experimental studies on compressor and turbine performances of motor-driven ACM. Hou et al. [10] carried out durability and stability characteristics of compliant foil journal bearing with elastic support by theory and experimental methods. They found this compliant foil journal bearing with elastic support can steadily run the turbo expander with a $25.0 \mathrm{~mm}$ diameter rotor revolving at $14.8 \times 10^{4} \mathrm{r} / \mathrm{min}$ and had excellent performance in terms of stability and durability. Heshmat [11] used coupled finite element and finite difference methods to analyze gas-lubricated foil-thrust bearings and provided an efficient technique to deal with the complex structural compliance of various foil bearings. Chen et al. [12, 13] conducted an experimental study on the nonlinear dynamic characteristics of a high-speed rotor-gas lubrication bearing system. Their experimental results indicated that gas whirl was the main cause of the nonlinear instability of the system. In addition, the two periodic bifurcations resulting from gas whirling led to the chaos vibration of the rotor-bearing system. Rotor dynamic characteristics are the key of stable operation of ACM, which reflect rotor response features and support characteristics of gas bearings. Morosi [14] presented a detailed mathematical model for hybrid lubrication of a compressible fluid-film journal bearing and built a multibody dynamics model of a global system comprising rotor and hybrid journal bearing to study the lateral dynamics of the system by Campbell diagrams and stability maps. Luis and Ryu [15] propose one way of restraining the critical speed region amplitude by changing the bearing supply gas pressure. Works of Reference [16] provided data on the ranges of stiffness and damping coefficients that made it possible to avoid the loss of stability in symmetric rotors running on selfacting bearings and in externally pressurized bearings.

The paper established the finite element model of the ACM rotor system, investigated effects of bearing stiffness and unbalanced exciting force on critical speed and response characteristics by modal and harmonic response analysis, and verified a resonance separation phenomenon on the ACM test rig.

\section{Air Cycle Machine Rotor System}

2.1. Rotor Structure Parameters. The structure diagram of the air cycle machine rotor is shown in Figure 1. The rotor structure with a single thrust disc of a radial turbine coaxial with a compressor is adopted. A pair of radial-thrust hybrid bearings is used to support the rotor. The main parameters of the rotor system are listed as follows: the material of the shaft is $3 G r 13$. The mass of the shaft is $533 \mathrm{~g}$. The material, mass, and polar rotational inertia of the turbine are $L Y 12,169 \mathrm{~g}$, and $9.53 \times 10^{4} \mathrm{~g} \mathrm{~mm}^{2}$, respectively. The material, mass, and polar rotational inertia of the compressor are LY12, $136 \mathrm{~g}$, and $7.41 \times 10^{4} \mathrm{~g} \mathrm{~mm}^{2}$, respectively.

The radial-thrust hybrid bearings are used in the air cycle machine. The structure of the bearing is shown in Figure 2. The material of bearings is graphite alloy. The "O" ring is installed on the bearing cup. The structural style for double rows of vertical air supply and orifice-restricted holes is adopted in the aerostatic bearings. The main structural sizes are listed in Table 1.

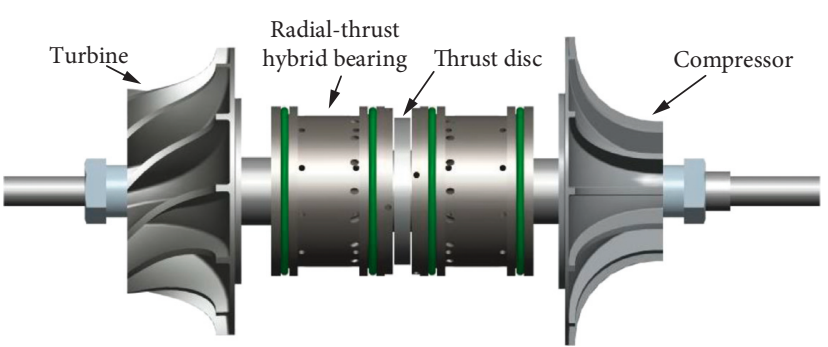

Figure 1: Structure diagram for air cycle machine rotor system.

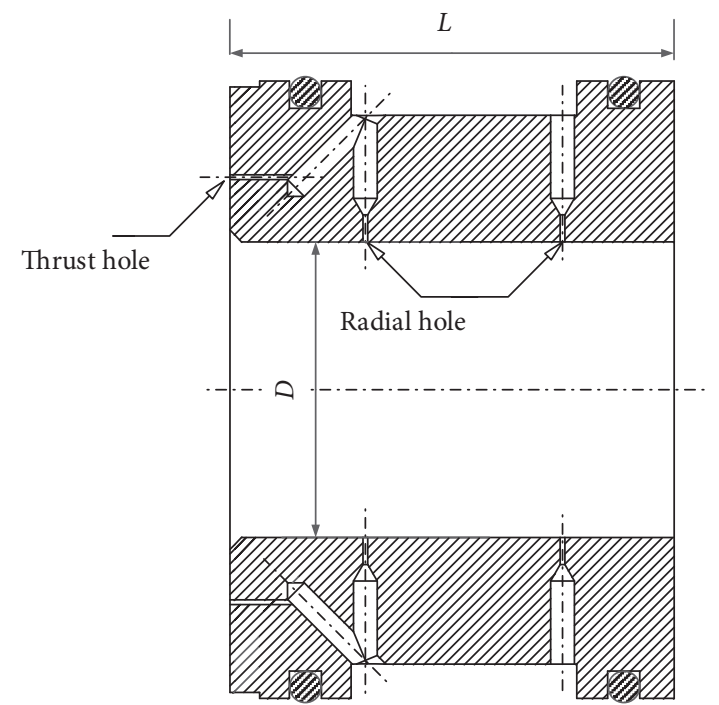

FIgURE 2: Structure diagram of radial-thrust hybrid gas bearing.

TABLE 1: : Main structural sizes for bearing.

\begin{tabular}{lcc}
\hline Geometric parameters & Symbol & Value \\
\hline Bearing width $(\mathrm{mm})$ & $L$ & 34 \\
Inner diameter $(\mathrm{mm})$ & $D$ & 25 \\
Radial clearance $(\mathrm{mm})$ & $C$ & 0.04 \\
Single-row radial hole number $(-)$ & $N_{1}$ & 10 \\
Single-row thrust hole number $(-)$ & $N_{2}$ & 16 \\
\hline
\end{tabular}

2.2. The Model of Rotor System. The element model of the ACM rotor system is built as shown in Figure 3. The rotor is divided into 14 shaft sections. Lumped mass points of the turbine and compressor are at the nodes of 4 and 13, respectively. The nodes of 7 and 10 are bearing nodes. The BEAM18X unit is used during the shaft section modeling. In the modeling process, the shaft section is in the middle of the adjacent nodes. The axis is along the $z$ direction. The axial section is located in the $x-y$ plane. The radial bearing is simulated by linkage unit COMBI214. Eight stiffness and damping coefficients are adopted to simulate radial bearings. The principal stiffness coefficients are $k_{11}$ and $k_{22}$, and the cross stiffness coefficients are $k_{12}$ and $k_{21}$. The principal damping coefficients are $c_{11}$ and $c_{22}$, and the cross damping coefficients are $c_{12}$ and $c_{21}$. In this paper, the same stiffness coefficients are set in two bearings, and the cross stiffness coefficients are not considered. The principal stiffness coefficients of $k_{11}$ and $k_{22}$ are equal to $2.5 \times 10^{6} \mathrm{~N} / \mathrm{m}$, and the following analysis results give 


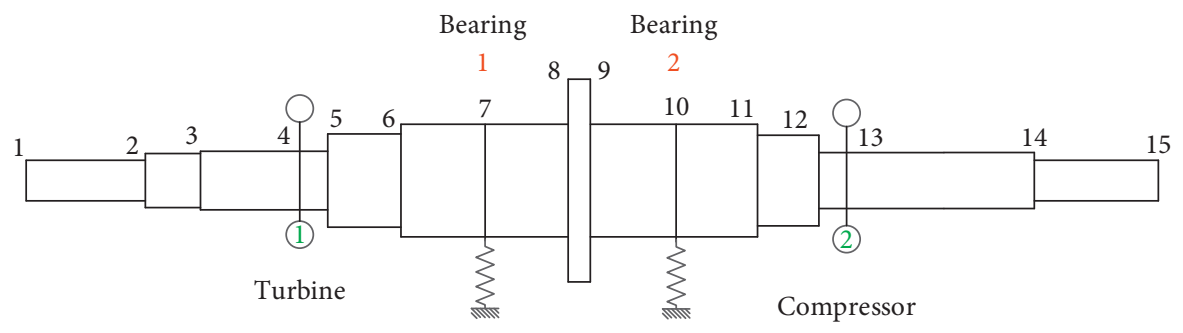

Figure 3: The FEA model of ACM rotor.

the effects of the change of stiffness on the critical speed characteristics. The damping coefficients are set at zero because gas damping effects are weaker. The axial mode and dynamic characteristics are not considered in this paper.

\section{Critical Speed Analysis of ACM Rotor System}

3.1. Critical Speed Calculation. Based on the established FEA model, the QRDamp modal method is used to calculate the front four-order natural frequencies under the different rotational speeds. Figure 4 gives the Campbell diagram at the principal stiffness coefficient of $2.5 \times 10^{6} \mathrm{~N} / \mathrm{m}$. The legend of "FW stable" in Figure 4 represents forward whirl. The legend of "BW stable" in Figure 4 represents backward whirl. The " $F=1 \times \operatorname{spin"}$ " is a synchronous force line of $s=1$. The actual motion of the rotor under unbalanced exciting force is the forward whirl. So, the critical speeds of the front four-order forward whirl are $9510 \mathrm{r} / \mathrm{min}, 21986 \mathrm{r} / \mathrm{min}, 127084 \mathrm{r} / \mathrm{min}$, and $190994 \mathrm{r} / \mathrm{min}$, respectively.

3.2. Critical Modal Shapes. The modal shapes are shown in Figures 5(a)-5(d). The corresponding modal motion shape of the first-order critical speed is conical whirling modal shape, and the whirl orbit appears dumbbell shape. The corresponding modal motion shape of the second-order critical speed is cylindrical whirling modal shape, and the whirl orbit appears cylindrical shape. The corresponding modal motion shape of the third-order critical speed is first-order bending modal shape, as shown in Figure 5(c). The corresponding modal motion shape of the fourth-order critical speed is second-order bending modal shape, as shown in Figure 5(d).

Gas bearing is one elastic support. Effects of different gas film stiffness on the critical speed are obvious. In the actual situations, the bearing supply gas pressure of aerostatic bearings changes from $0.20 \mathrm{MPa}$ to $0.80 \mathrm{MPa}$, and the corresponding bearing stiffness changes from $0.25 \times 10^{7} \mathrm{~N} / \mathrm{m}$ to $0.95 \times 10^{7} \mathrm{~N} / \mathrm{m}$. The critical speed changes with gas film stiffness, as shown in Figure 6 . The first- and second-order critical speed changes with a wide range. With the increasing bearing principal stiffness from $2.5 \times 10^{6} \mathrm{~N} / \mathrm{m}$ to $9.5 \times 10^{6} \mathrm{~N} / \mathrm{m}$, the first-order critical speed increases from $9,510 \mathrm{r} / \mathrm{min}$ to $18,385 \mathrm{r} / \mathrm{min}$, and the second-order critical speed increases from $21,986 \mathrm{r} / \mathrm{min}$ to $43,390 \mathrm{r} / \mathrm{min}$. The corresponding values increase $93.32 \%$ and $97.35 \%$, respectively. In Section 3.1, the conclusions can be obtained that the first-order critical speed is conical whirling motion, and the second-order critical speed is cylindrical whirling

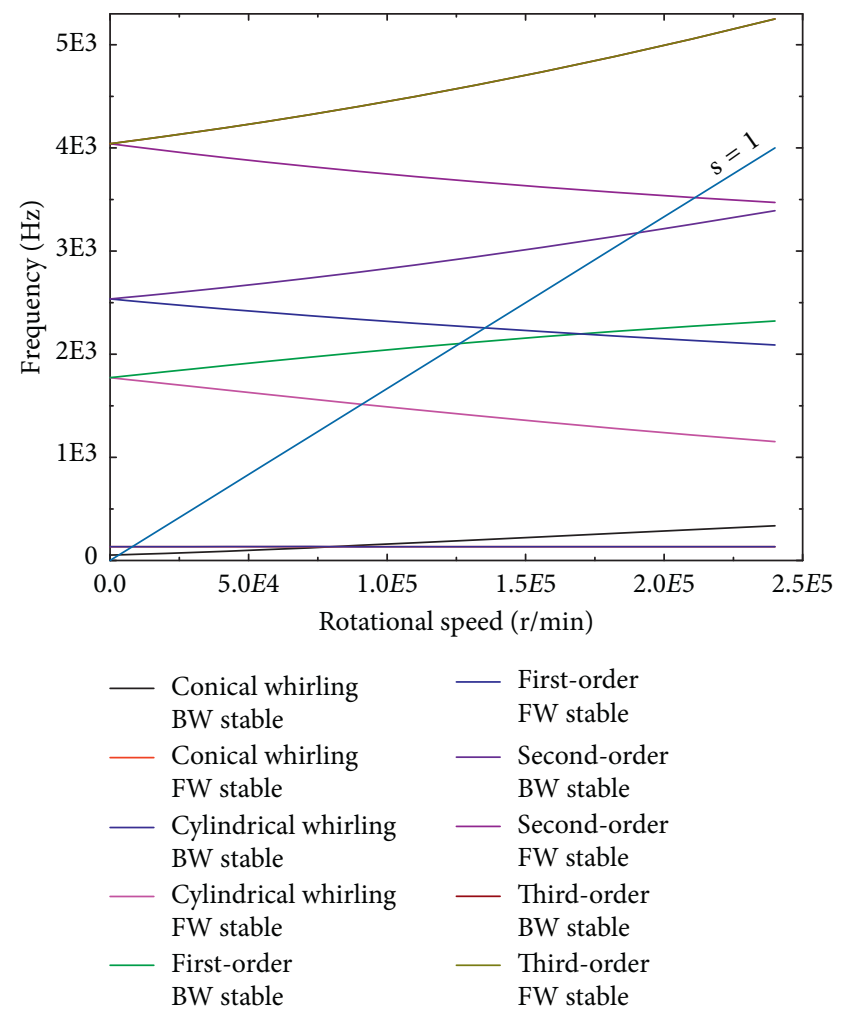

Figure 4: Campbell diagram of ACM rotor.

motion. The front two-order modal features reflect the characteristics of the gas bearing when the rotor is in a rigid state. So, the front two-order critical speed increases with the bearing stiffness obviously.

The third-order critical speed increases from $127,084 \mathrm{r} / \mathrm{min}$ to $129,235 \mathrm{r} / \mathrm{min}$ with the increase of bearing principal stiffness. The fourth-order critical speed increases from $190,994 \mathrm{r} / \mathrm{min}$ to $191,850 \mathrm{r} / \mathrm{min}$. The corresponding values increase by $1.69 \%$ and $0.45 \%$, respectively. So, the third and fourth critical speed remains about unchanged. That is because the third- and fourth-order critical speed reflects the rotor feature. The rotor stiffness is larger than the bearing stiffness, and the effect of the change of bearing stiffness on the third- and fourth-order critical speed is lesser.

\section{Unbalance Response Analysis}

The rotor unbalance includes force unbalance and couple unbalance, which is formed by mass unbalance. During the dynamic balance, the force and couple systems are projected 

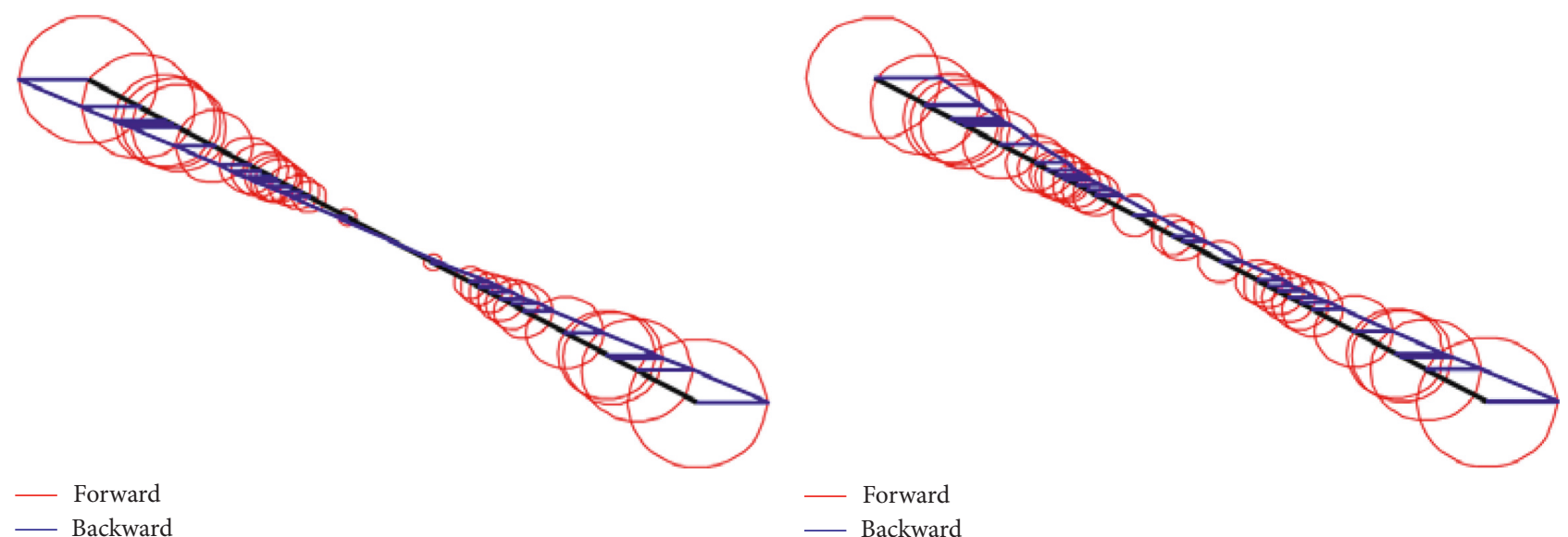

(a)

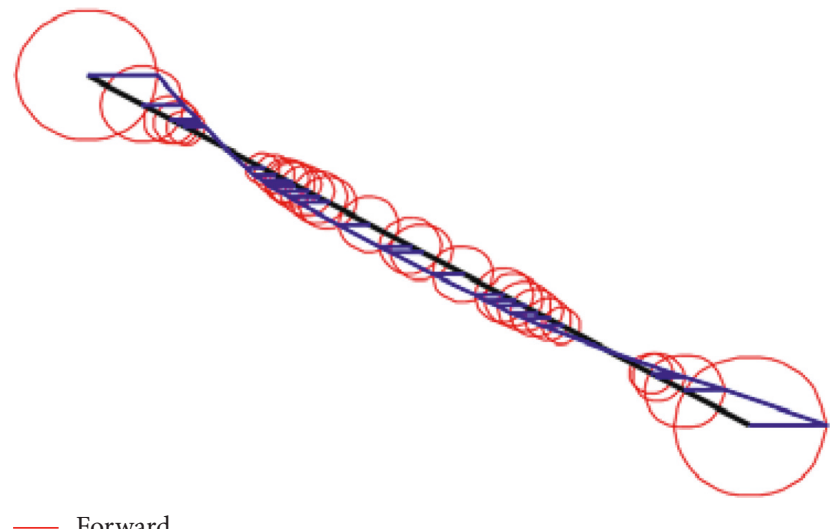

- Forward
Backward

(b)

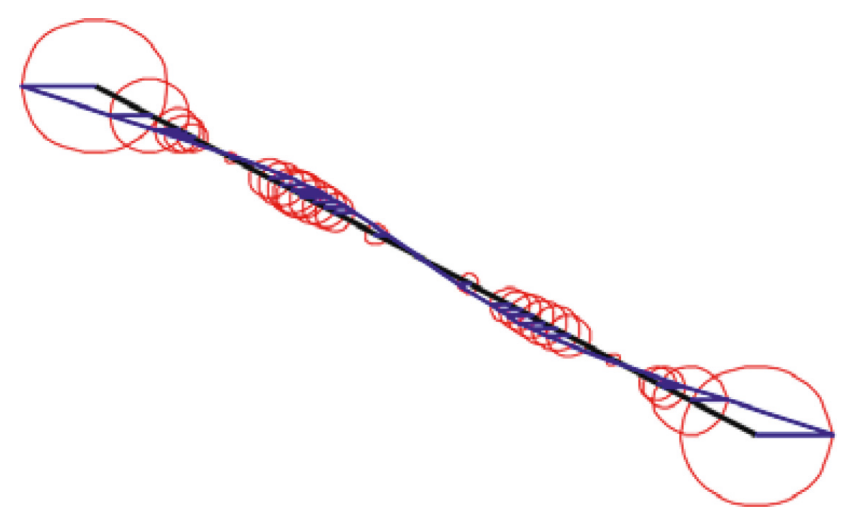

- Forward

(c)

(d)

FIGURE 5: Modal shapes for every order critical speed. (a) Conical whirling modal shape. (b) Cylindrical whirling modal shape. (c) Firstorder bending modal shape. (d) Second-order bending modal shape.

to the correcting plane, and dynamic balance is done by removing or adding the mass. The method of removing the mass on the back of the turbine and compressor is used to balance the ACM rotor. The different unbalanced exciting force $F_{0}$ is applied on the back of the turbine and compressor, and the rotor unbalance response characteristics are discussed in the following analysis. The conditions for unbalanced exciting force are listed in Table 2. The location of unbalanced exciting force for Condition 1 is shown in Figure 7.

The unbalanced force of eccentric mass is shown in

$$
F_{0}=m e \omega^{2} .
$$

Here, $m$ is the eccentric mass, $e$ is the distance from the center of the mass to the geometric center, and $\omega$ is the rotational speed.

The rotational speed $\omega$ is synchronous with excitation frequency $\Omega$. So, Equation (1) can be rewritten as

$$
F_{0}=m e \Omega^{2} .
$$

Equation (2) is broken down into $Y$ and $Z$ coordinates, which are shown in Equations (3) and (4) by a complex number.

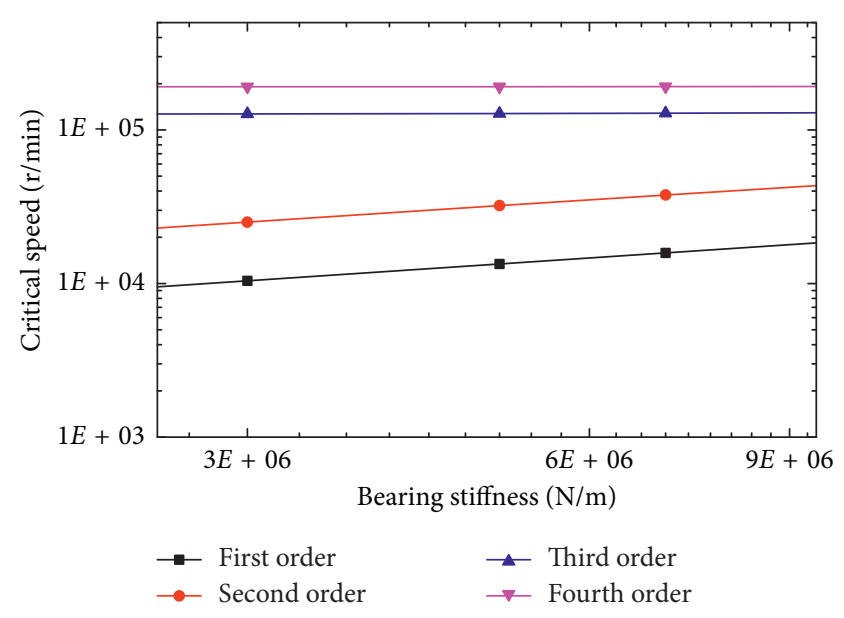

Figure 6: The critical speed changing with gas film stiffness.

$$
\begin{aligned}
& F_{y}=F_{0} \cos (\Omega t)=F_{0} e^{j \Omega t}, \\
& F_{z}=F_{0} \sin (\Omega t)=-F_{0} e^{j \Omega t} .
\end{aligned}
$$


TABle 2: Applying condition for unbalanced exciting force.

\begin{tabular}{lcccc}
\hline Conditions & Turbine & Compressor & Unbalanced exciting force & Bearing stiffness \\
\hline 1 & $F_{0} e^{j \Omega t}$ & $F_{0} e^{j \Omega t}$ & Same amplitude and same phase & Isotropy \\
2 & $F_{0} e^{j \Omega t}$ & $F_{0} e^{j\left(\Omega \mathrm{t}-90^{\circ}\right)}$ & Anisotropy & Isotropy \\
3 & $F_{0} e^{j \Omega t}$ & $F_{1} e^{j \Omega t}$ & Dame amplitude and different phase & Anisotropy \\
4 & $F_{0} e^{j \Omega t}$ & $F_{1} e^{\left(\Omega t-90^{\circ}\right)}$ & Different amplitude and same phase & Isotropy \\
Anisotropy & Isotropy & Anisotropy \\
\hline
\end{tabular}

Annotation. Unbalanced exciting force: different phase means the compressor falls $90^{\circ}$ behind the turbine. Different amplitude means $F_{1}=1 / 2 F_{0}$. Bearing stiffness anisotropy: the bearing principal stiffness in the horizontal direction is equal to $1 / 2$ of the bearing principal stiffness in the vertical direction.

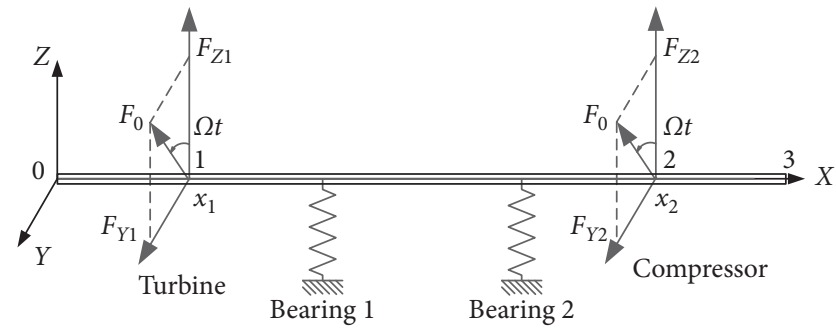

FIGURE 7: Applying position for unbalanced exciting force.

Disposing of the initial conditions in ANSYS, the value of $m e$ is only inputted, and $\Omega^{2}$ automatically joins the calculation. When the option "RATIO" of the order "SYNCHRO" is blank, the eccentric mass stimulates unbalanced force of the same phase. Set $m e_{1}=2.0 \times 10^{-5} \mathrm{~kg} \cdot \mathrm{m}$ at the turbine end, and set $m e_{1}=2.0 \times 10^{-5} \mathrm{~kg} \cdot \mathrm{m}$ at the compressor end. The response characteristics of the nodes 0 and 3 in Figure 7 and support reaction for bearings 1 and 2 are emphatically analyzed. Because design speed of ACM $(60000 \mathrm{r} / \mathrm{min})$ is far below the third-order critical speed, the response characteristics of the nodes 0 and 3 and support reaction for bearings 1 and 2 are emphatically analyzed during first- and second-order critical speed regions.

\subsection{Analysis of Results}

\subsubsection{Condition 1}

(1) Bearing Stiffness Isotropy. Taking the characteristics in the horizontal direction in Figure 8 as analysis, the amplitude of point B for the second-order critical speed (cylindrical whirling critical speed) is obviously higher than the amplitude of point A for the first-order critical speed (conical whirling critical speed). When the rotor passes the cylindrical whirling critical speed region, the phase of the nodes is consistent with that of the applied unbalanced exciting force, and so, the amplitude of the cylindrical whirling critical speed region is sharply stimulated. The amplitude and phase response of the nodes 0 and 3 for the front two-order critical speed is coincident in Figures 8(a) and 8(b). The critical circle B of the cylindrical whirling critical speed region is larger than the critical circle A of the conical whirling critical speed region in Figure $8(\mathrm{c})$. Each circle skirts $180^{\circ}$ in the polar diagram. The support reaction for bearings 1 and 2 is also largest in the cylindrical whirling critical speed region in Figure $8(\mathrm{~d})$.
(2) Bearing Stiffness Anisotropy. When bearing stiffness is anisotropic, the front two-order critical speed appears with differences between the horizontal direction and vertical direction, as shown in Figure 9(a). The horizontal bearing stiffness is smaller than the vertical bearing stiffness, and the critical speed value in the horizontal direction is smaller than the value in the vertical direction. In Figure 9(b), the variation range of the phase for the node 0 increases in the conical whirling critical speed region, which is larger than $180^{\circ}$. The amplitude response and bearing support reaction are also larger in the cylindrical whirling critical speed region, and the corresponding maximum response value occurs at the different speed in different directions in Figures 9(a) and 9(e). Compared with results of bearing stiffness isotropy, salient points A and C appear in Figure 9(c). As shown in Figure 9(d), amplitude response in the vertical direction for nodes 0 and 3 is consistent with different power frequencies. The characteristics of bearing support reaction and the node amplitude response are similar, and the amplitude in the conical whirling critical speed region is restrained in Figure 9(f). The corresponding frequency with the peak of bearing support reaction is different under different bearing stiffness.

\subsubsection{Condition 2}

(1) Bearing Stiffness Isotropy. The solving results under the same bearing stiffness in Condition 2 are given in Figure 10. When the phase of applied unbalanced exciting force has phase quadrature, resonance separation occurs in the conical whirling critical speed region. There are two resonance peaks, whose frequencies, respectively, are $145.00 \mathrm{~Hz}$ (A) and $158.75 \mathrm{~Hz}$ (B), and whose amplitude are close, as shown in Figure 10(a). The phase response of nodes 0 and 3 in the vertical direction shows a similar trend in Figure 10(b). The phases of resonance separation points $\mathrm{A}$ and $\mathrm{B}$ differ $90^{\circ}$. Two circles are formed with similar radius, which, respectively, are $A$ and $B$ in Figure 10(c). Meanwhile, the phase range of the conical whirling critical speed region changes in the range of $180^{\circ}$. Resonance separation does not occur in the cylindrical whirling critical speed region. There is only one circle $\mathrm{C}$ in the cylindrical whirling critical speed region. Resonance amplitude in the conical whirling critical speed region is larger than that in the cylindrical whirling critical speed region, and the characteristics of bearing support reaction are similar to amplitude response, as shown in Figure 10(d). 


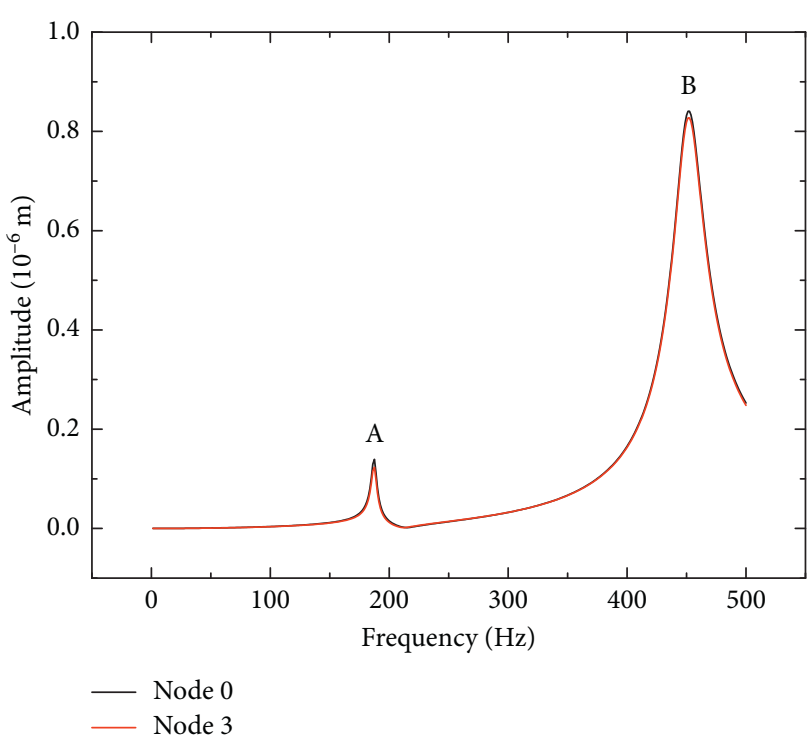

(a)

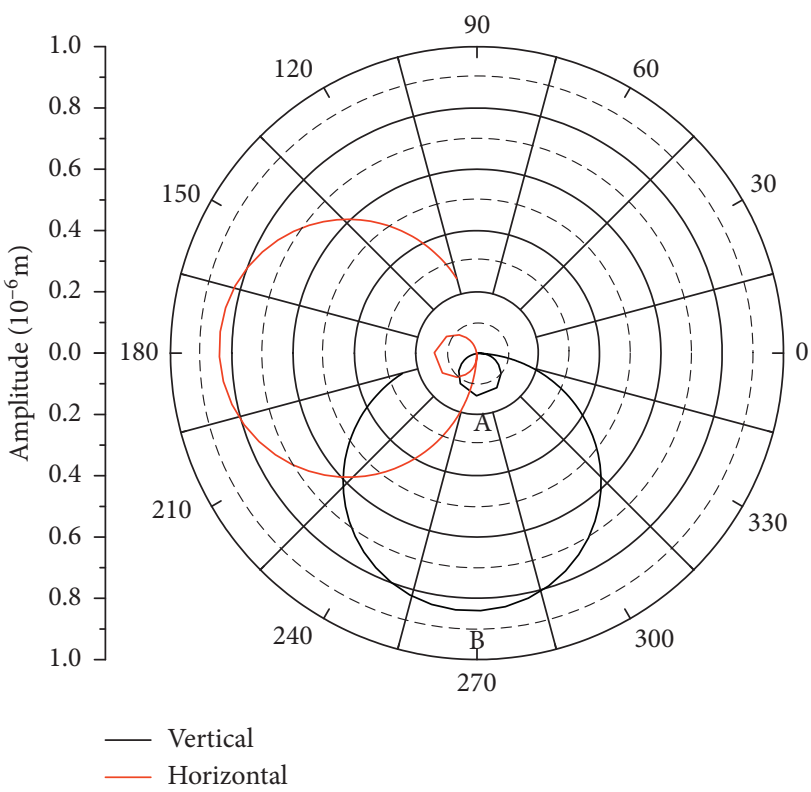

(c)

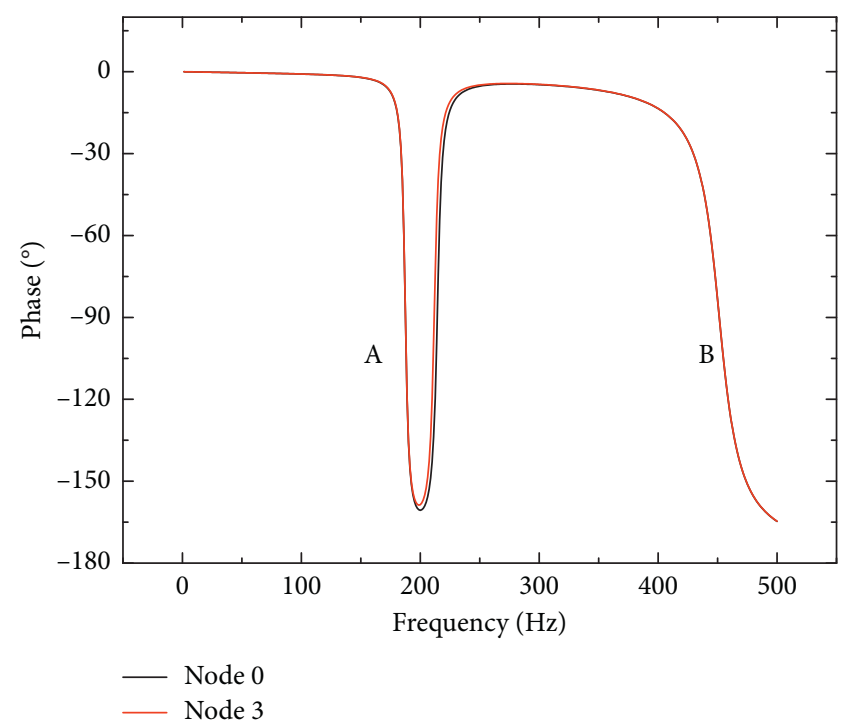

(b)

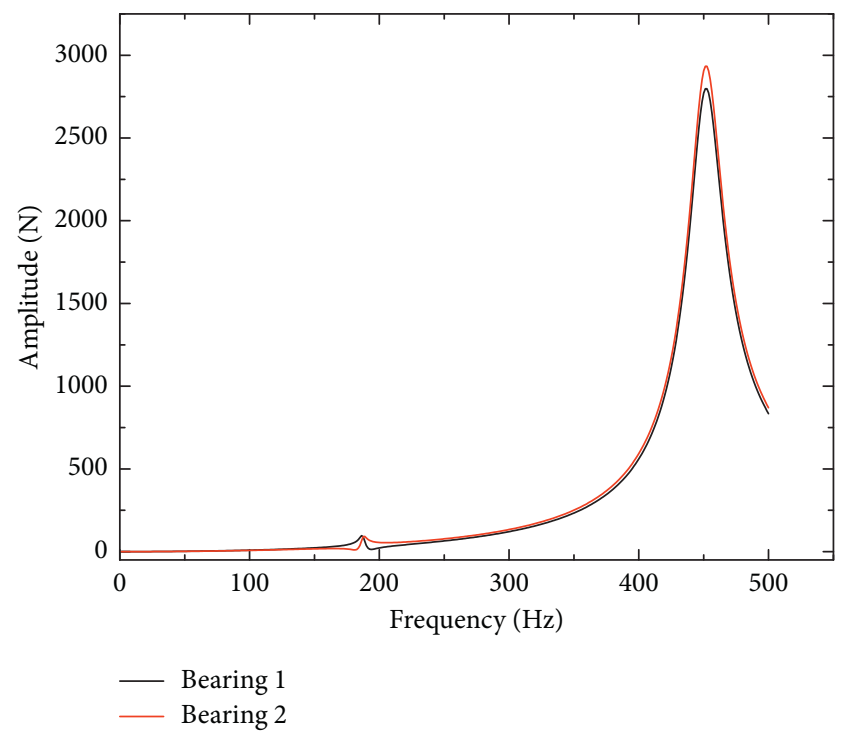

(d)

FIgURE 8: Rotor response and support reaction characteristics for Condition 1 (isotropic bearing stiffness). (a) Amplitude response at vertical direction. (b) Phase response at vertical direction. (c) Polar diagram at node 0. (d) Support reaction at vertical direction.

Effects of bearing stiffness on the frequency of separation points are given in Table 3 . The frequencies of resonance separation points $\mathrm{A}$ and $\mathrm{B}$ appear in increasing trend with the increase of bearing stiffness. The difference value of separation points also shows a little increasing trend.

(2) Bearing Stiffness Anisotropy. A resonance separation phenomenon occurs both in the conical whirling critical speed region at the horizontal and vertical direction under anisotropic bearing stiffness in condition 2. The resonance separation phenomenon does not occur in the cylindrical whirling critical speed region. As shown in Figure 11(a), the main peak frequencies of resonance separation in the conical whirling critical speed region at the horizontal and vertical directions are marked by $\mathrm{A}$ and $\mathrm{B}$. Resonance peaks in the cylindrical whirling critical speed region at the horizontal and vertical directions are marked by $\mathrm{C}$ and $\mathrm{D}$. The amplitude of the resonance separation point in the conical whirling critical speed region appears with opposite features in different directions. Because bearing stiffness in the horizontal direction is smaller than that in the vertical direction, the amplitude of resonance separation point $A$ is larger than that of point $\mathrm{F}$ in the horizontal direction, and the amplitude of resonance separation point $\mathrm{E}$ is smaller than that of point B. Meanwhile, the frequency of resonance separation point $\mathrm{A}$ is equal to that of point $\mathrm{E}$, and the frequency of resonance separation point $B$ is equal to that of point F. 

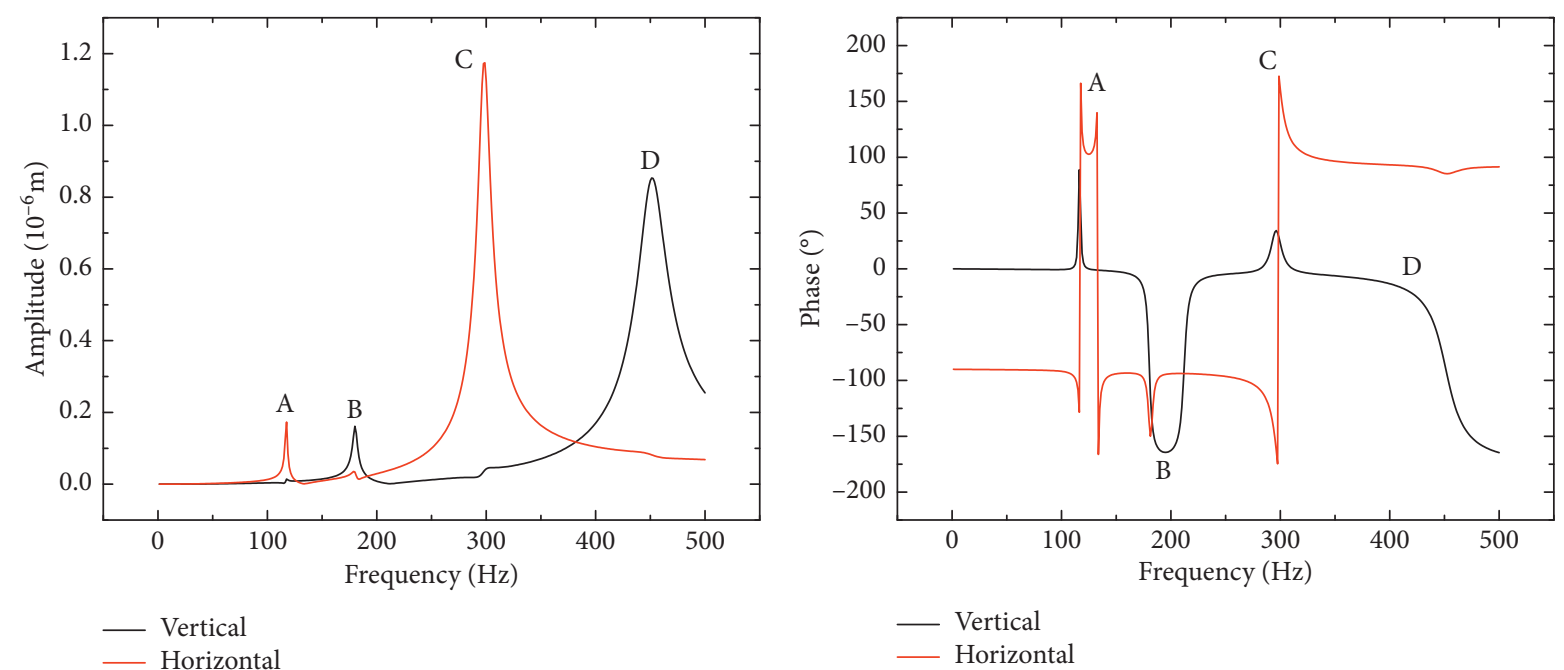

(a)
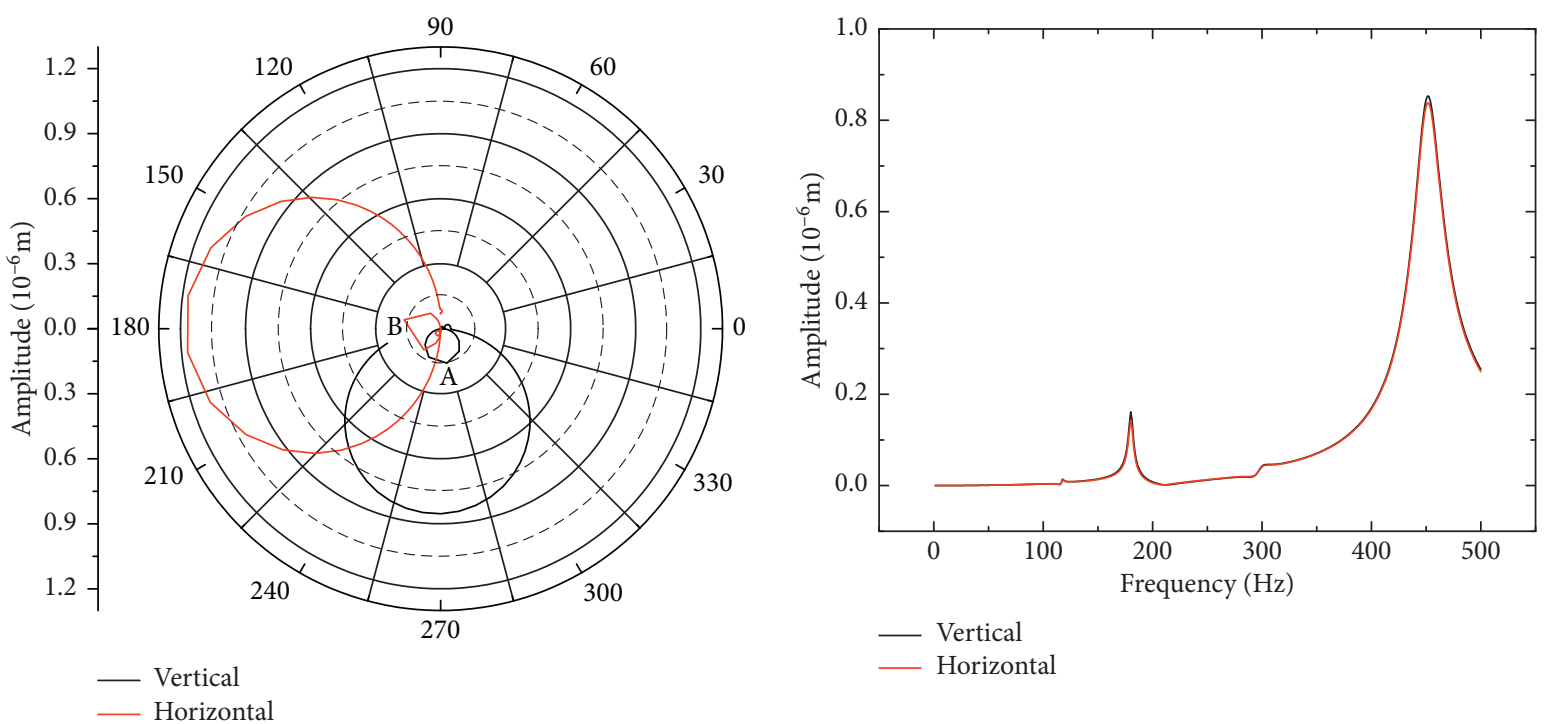

(c)

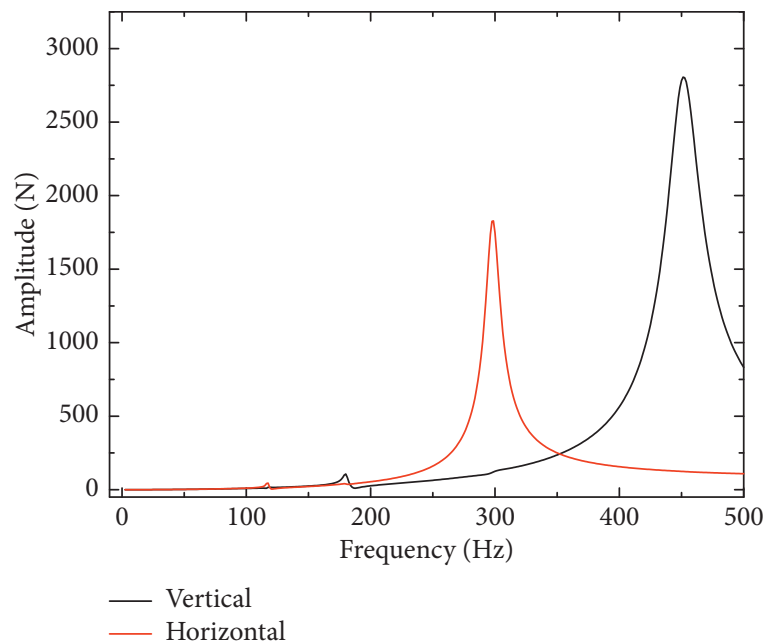

(e)

(d)

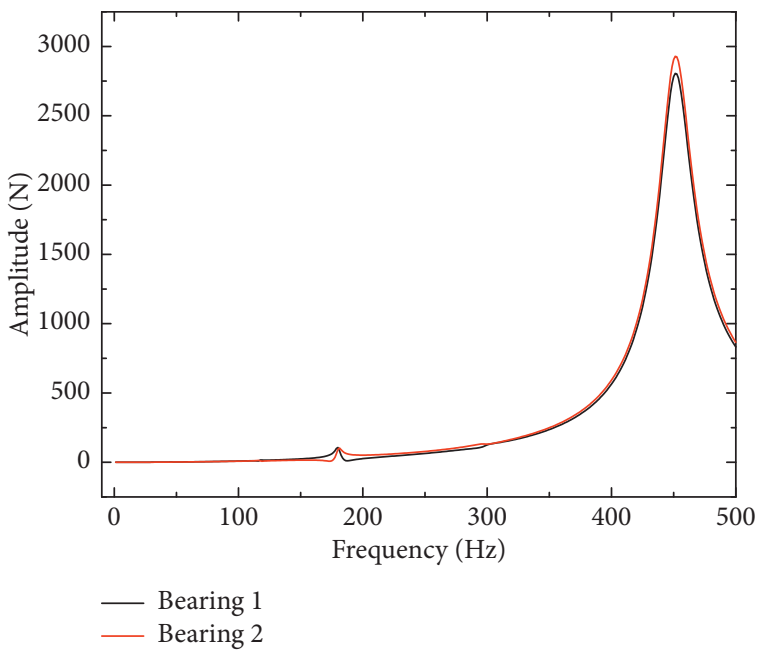

(f)

FIgURE 9: Rotor response and support reaction characteristics for Condition 1 (anisotropic bearing stiffness). (a) Amplitude response at node 0. (b) Phase response at node 0. (c) Polar diagram at node 0. (d) Amplitude response at vertical direction. (e) Support reaction of bearing 1. (f) Support reaction at vertical direction. 

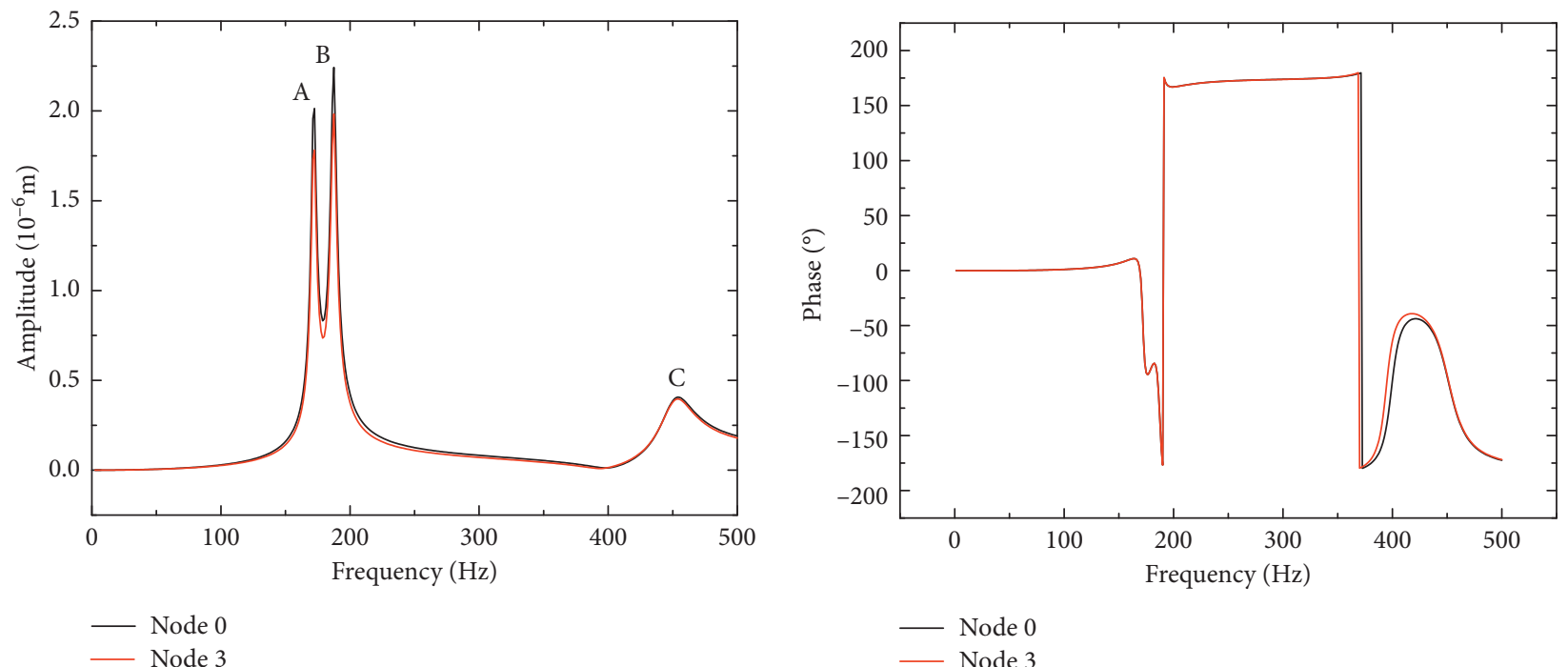

(a)
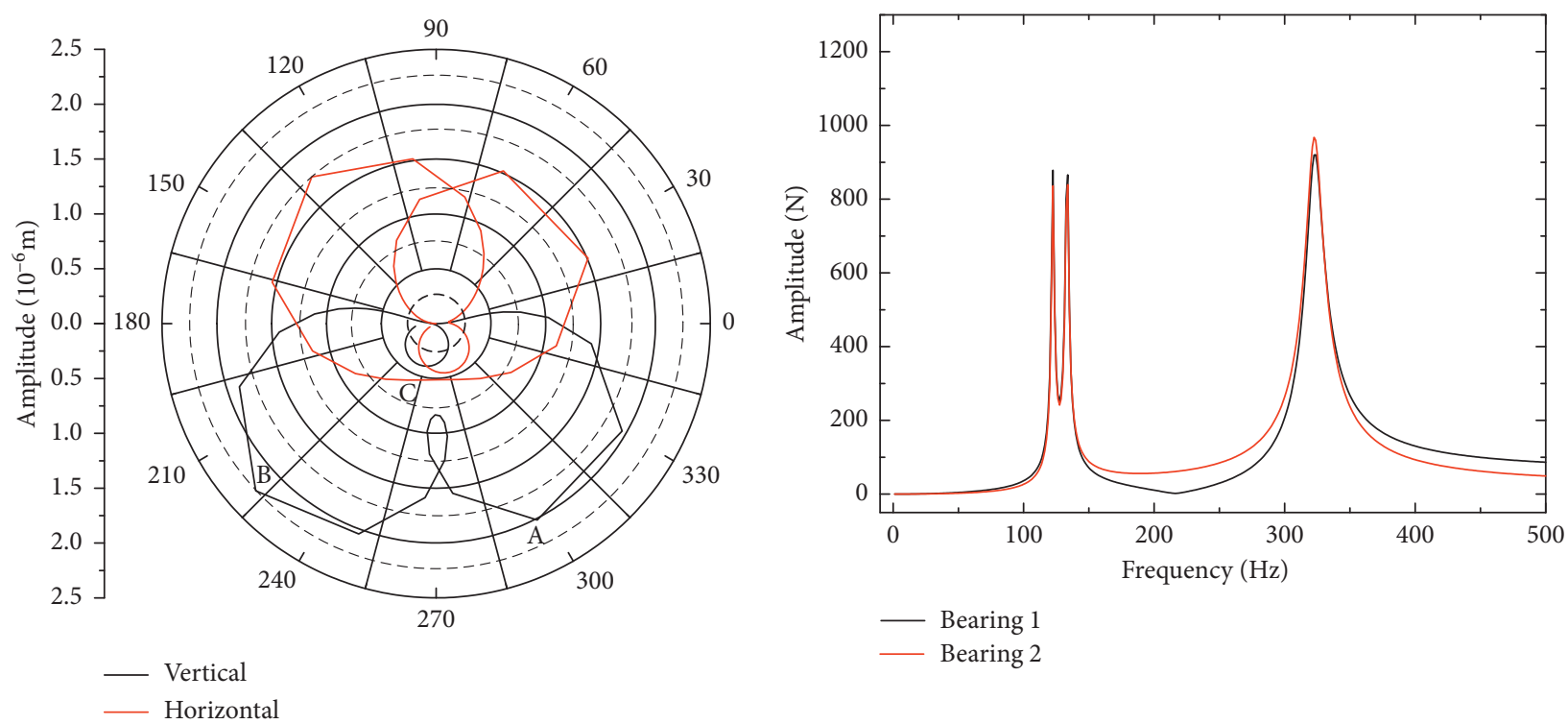

(c)

(d)

FIgURE 10: Rotor response and support reaction characteristics for Condition 2 (isotropic bearing stiffness). (a) Amplitude response at vertical direction. (b) Phase response at vertical direction. (c) Polar diagram at node 0. (d) Support reaction at vertical direction.

TABle 3: Resonance separation for the critical speed region.

\begin{tabular}{lcccc}
\hline \multirow{2}{*}{$\begin{array}{l}\text { Bearing stiffness } \\
(\mathrm{N} / \mathrm{m})\end{array}$} & $\begin{array}{c}\text { Conical whirling critical speed region } \\
\text { Separation point A } \\
(\mathrm{Hz})\end{array}$ & $\begin{array}{c}\text { Separation point B } \\
(\mathrm{Hz})\end{array}$ & $\begin{array}{c}\text { Difference value } \\
(\mathrm{Hz})\end{array}$ & $\begin{array}{c}\text { Cylindrical whirling critical speed C } \\
(\mathrm{Hz})\end{array}$ \\
\hline $2.5 \times 10^{6}$ & 145.00 & 158.75 & 13.75 & 385.00 \\
$3.0 \times 10^{6}$ & 158.75 & 173.75 & 15.00 & 421.25 \\
$3.5 \times 10^{6}$ & 172.5 & 187.50 & 15.00 & 453.75 \\
$4.0 \times 10^{6}$ & 183.75 & 200.00 & 16.25 & 485.00 \\
\hline
\end{tabular}

In Figure 11(c), the resonance circle at the vertical direction in the conical whirling critical speed region is from small to big, and the phase range changes in the range of $180^{\circ}$. The circle $\mathrm{D}$ is the cylindrical whirling critical circle. The feature of bearing support reaction is similar to amplitude response, as shown in Figure 11(d).

\subsubsection{Condition 3}

(1) Bearing Stiffness Isotropy. When bearing stiffness is isotropic under condition 3 , the resonance separation phenomenon does not occur in Figures 12(a)-12(d). The amplitude in the conical whirling critical speed region is 


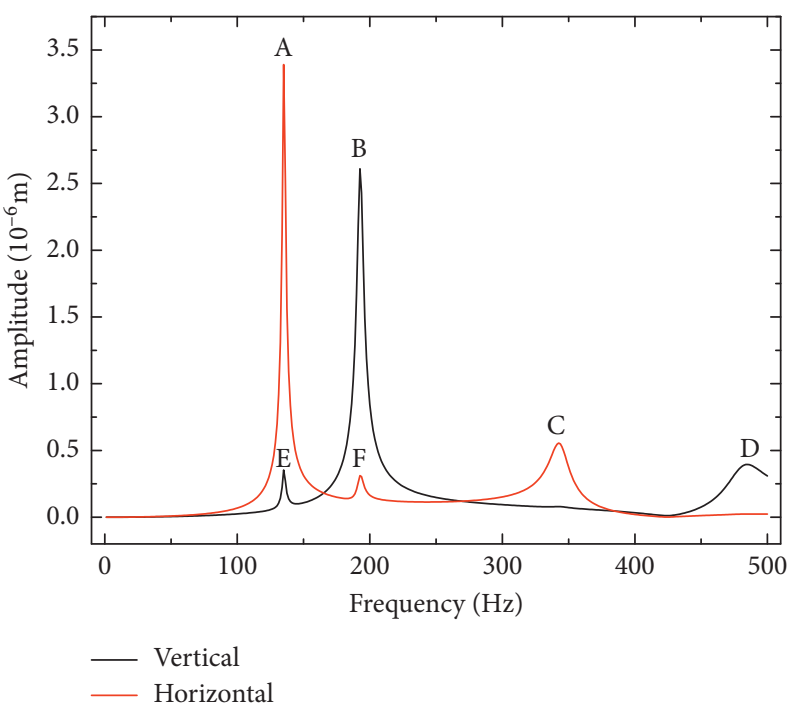

(a)

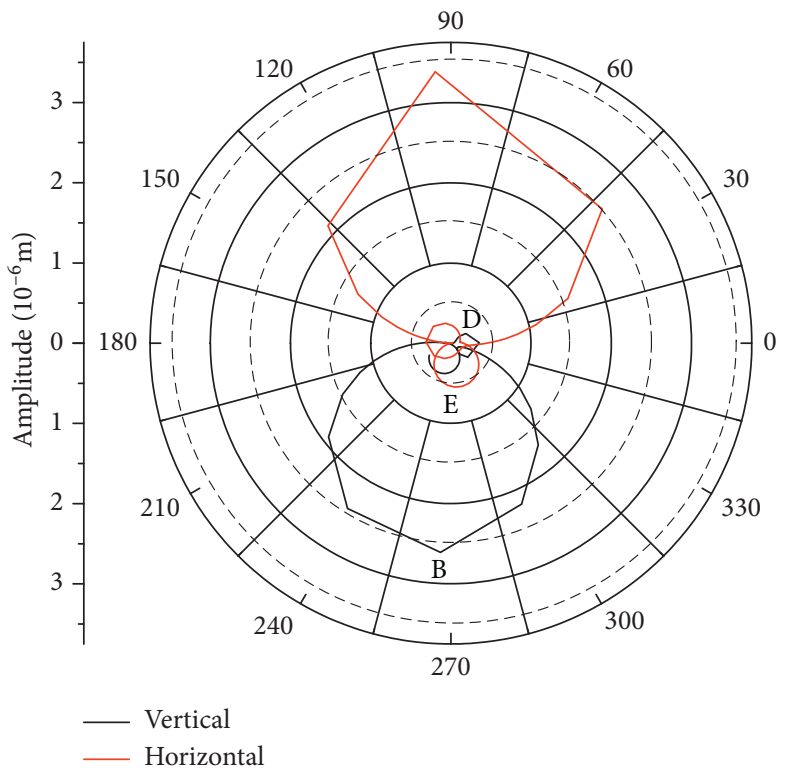

(c)

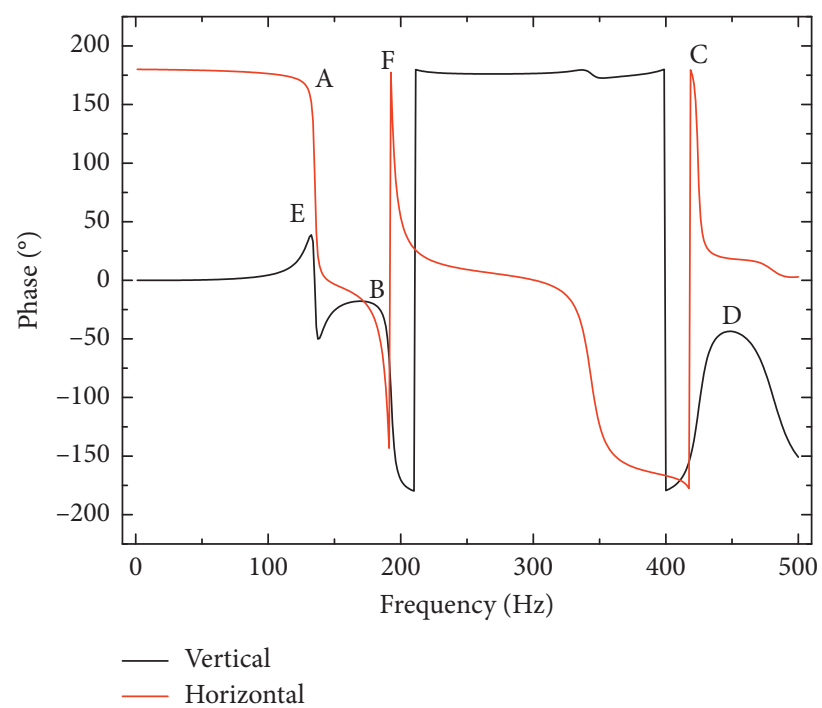

(b)

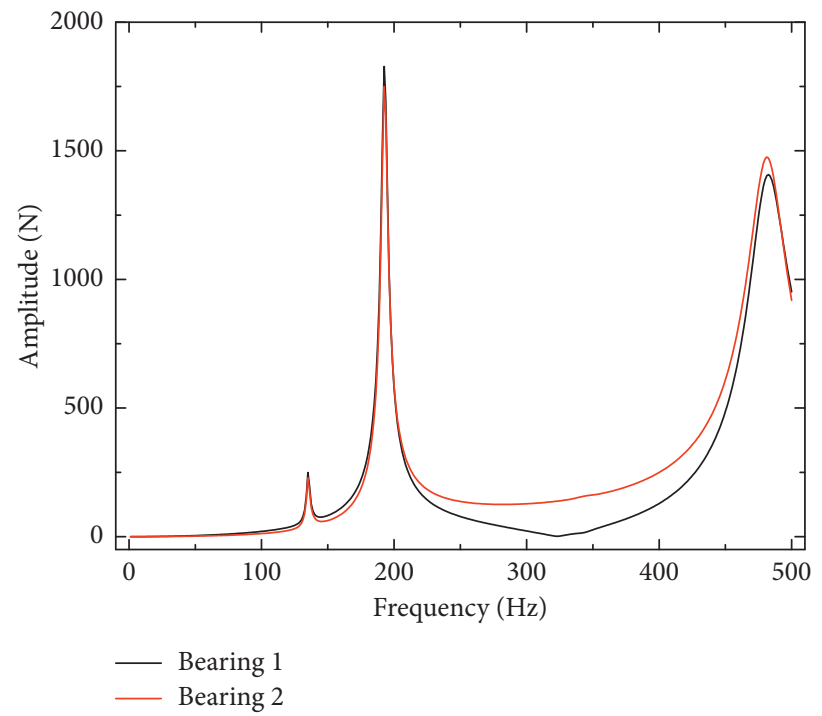

(d)

FIGURE 11: Rotor response and support reaction characteristics for condition 2 (anisotropic bearing stiffness). (a) Amplitude response at node 0. (b) Phase response at node 0. (c) Polar diagram at node 0. (d) Support reaction at vertical direction.

larger than that in the cylindrical whirling critical speed region. The difference is that bearing support reaction of bearings 1 and 2 in the front two-order critical speed region is approximate. The phase range of conical and cylindrical whirling critical speed regions both changes in the range of $180^{\circ}$ in Figure $12(\mathrm{c})$.

(2) Bearing Stiffness Anisotropy. The results in this condition are similar to the results of condition 2 in the anisotropic bearing stiffness. The resonance separation phenomenon occurs in the conical whirling critical speed region at the horizontal and vertical directions in Figure 13(a). The amplitude of the resonance separation point appears opposite features between the horizontal and vertical directions because of different bearing stiffness at two directions.
Meanwhile, the response characteristics for nodes 0 and 3 at the same direction are consistent in Figure 13(b).

Bearing support reaction of bearing 1 and 2 in the conical whirling critical speed region is consistent with amplitude response, and bearing support reaction of bearings 1 and 2 in the cylindrical whirling critical speed region is relatively larger, which is different from characteristics of response in the cylindrical whirling critical speed region, as shown in Figure 13(d).

\subsubsection{Condition 4}

(1) Bearing Stiffness Isotropy. The resonance separation phenomenon appears in the conical whirling critical speed 


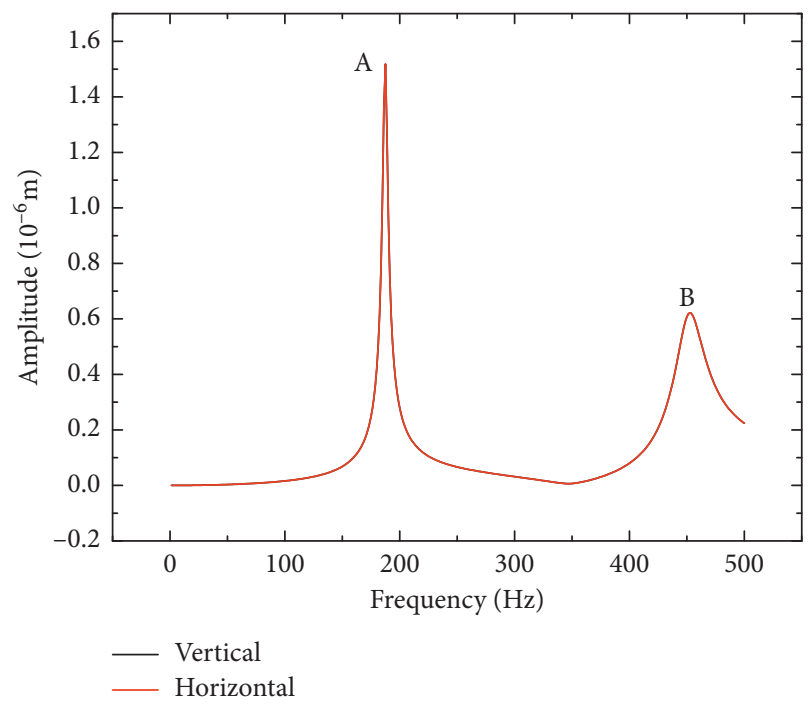

(a)

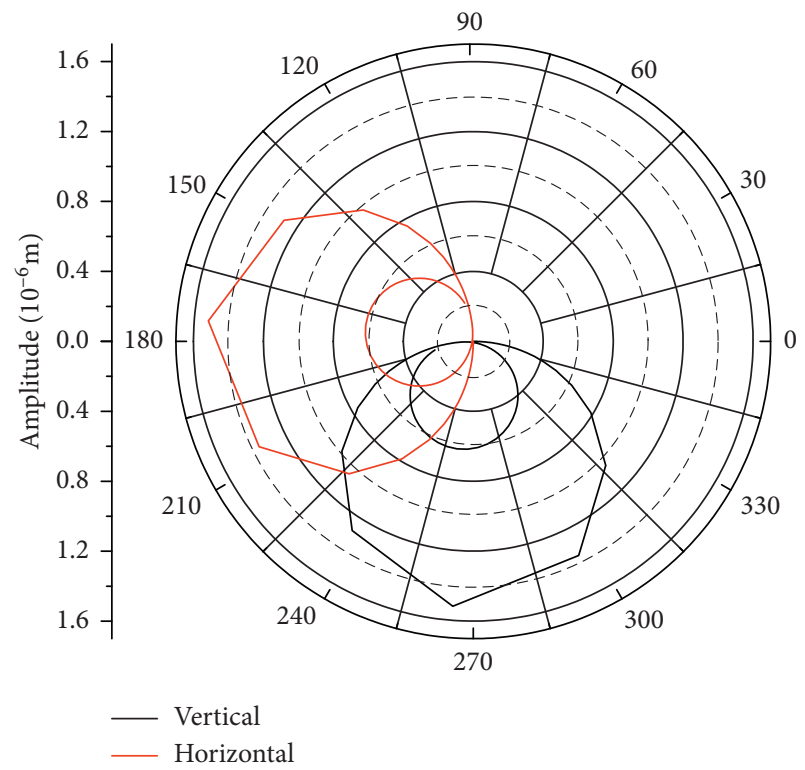

(c)

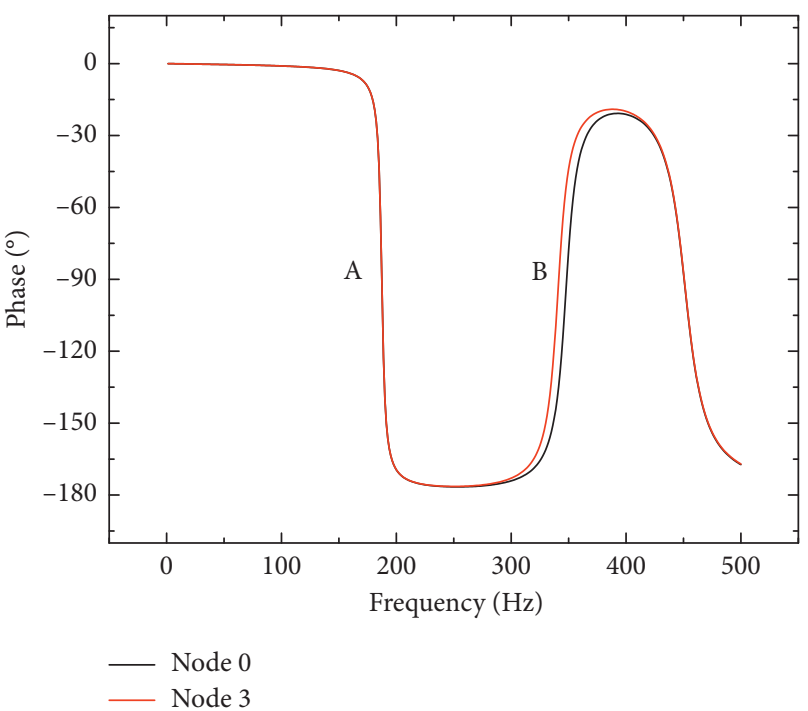

(b)

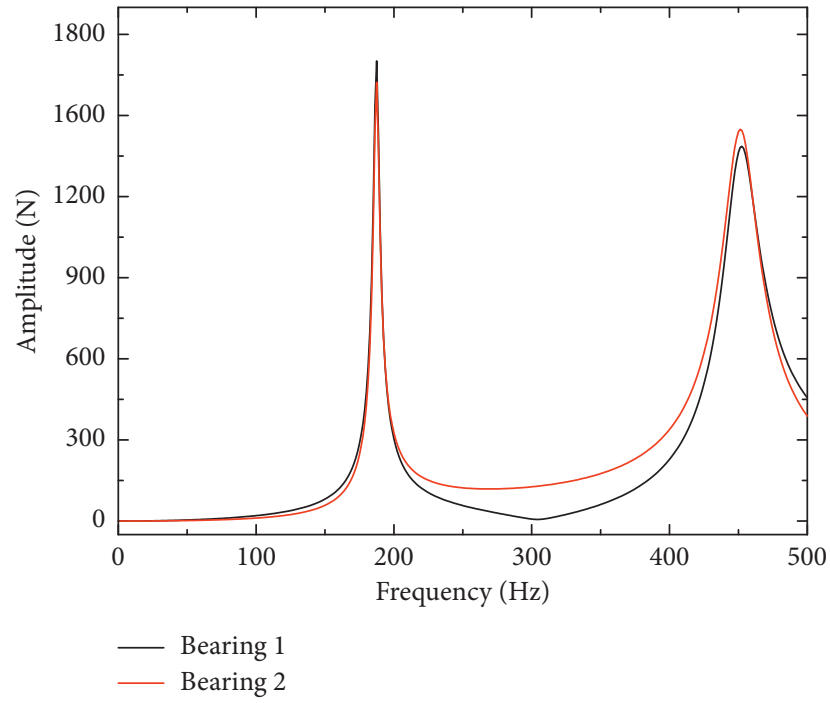

(d)

FIGURE 12: Rotor response and support reaction characteristics for condition 3 (isotropic bearing stiffness). (a) Amplitude response at node 0. (b) Phase response for vertical direction. (c) Polar diagram at node 0. (d) Support reaction at vertical direction.

region at the horizontal and vertical directions. Resonance separation points are A and B, respectively, which is similar to condition 2 when bearing stiffness is isotropic. The amplitude in the cylindrical whirling critical speed region at the vertical direction is restrained in Figure 14(a). The amplitude response at nodes 0 and 3 at the same direction is consistent in Figure 14(b). The phase appears fluctuated near resonance separation points $\mathrm{A}$ and $\mathrm{B}$, and the phase range of conical whirling critical speed region still changes in the range of $180^{\circ}$ in Figures 14(c)-14(d). Two circles are formed with similar radius, which, respectively, are A and $B$ in the polar diagram of Figure 14(e). The phase feature in this condition is close to that in condition 2 under bearing stiffness isotropy. The resonance separation phenomenon also occurs in the conical whirling critical speed region for bearing support reaction. The amplitude of bearing support reaction in the cylindrical whirling critical speed region is larger than that in the conical whirling critical speed region, as shown in Figure 14(f).

(2) Bearing Stiffness Anisotropy. As shown in Figure 15(a), the resonance separation phenomenon appears in the conical whirling critical speed region at the horizontal direction, but that does not occur at the vertical direction. The amplitude response at the horizontal direction in the critical speed region is relatively smaller, and the amplitude in the cylindrical whirling critical speed region at the horizontal direction is zero. Resonance separation does not occur at the vertical direction, and the amplitude in the conical whirling critical speed region is larger at node 0 . That is because applied unbalanced exciting force at the vertical direction is smaller than that at the horizontal direction. 


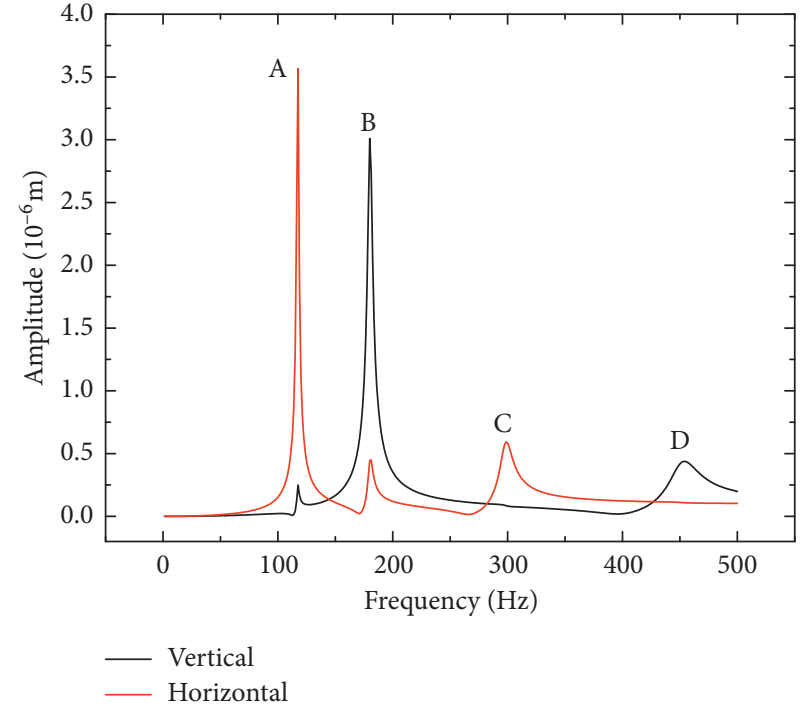

(a)

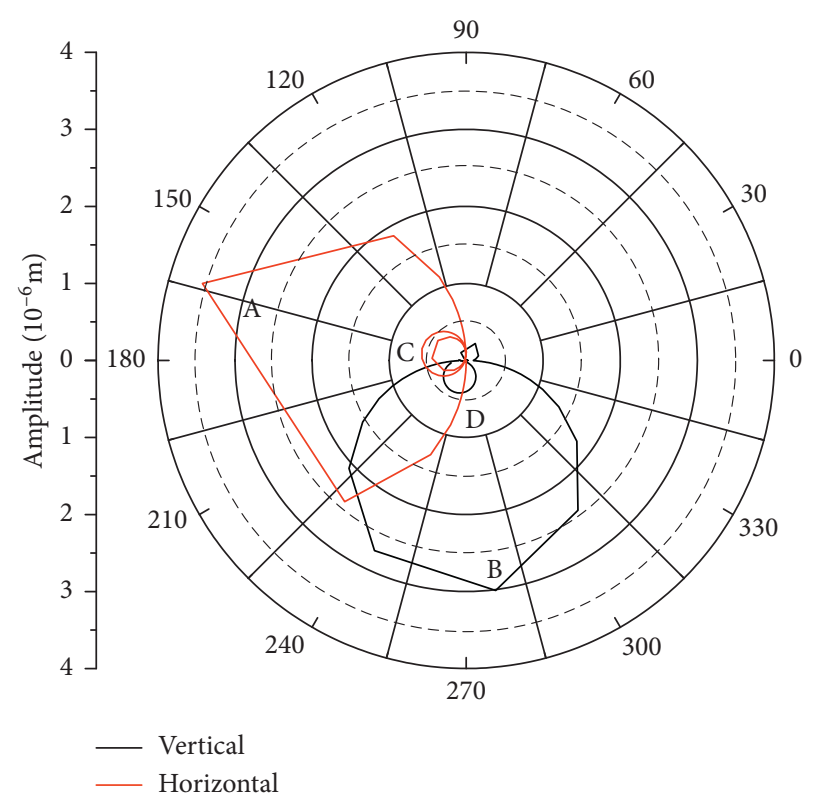

(c)

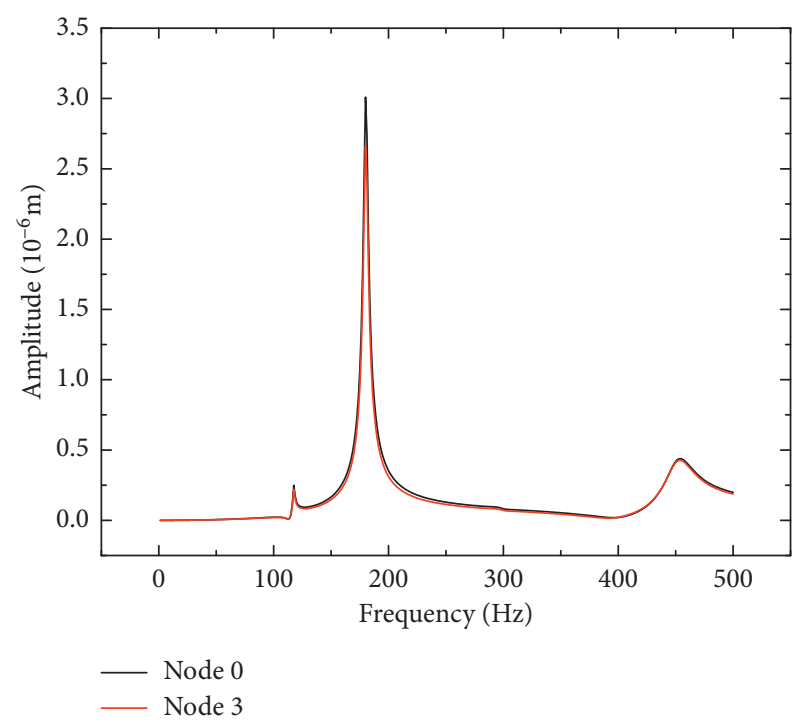

(b)

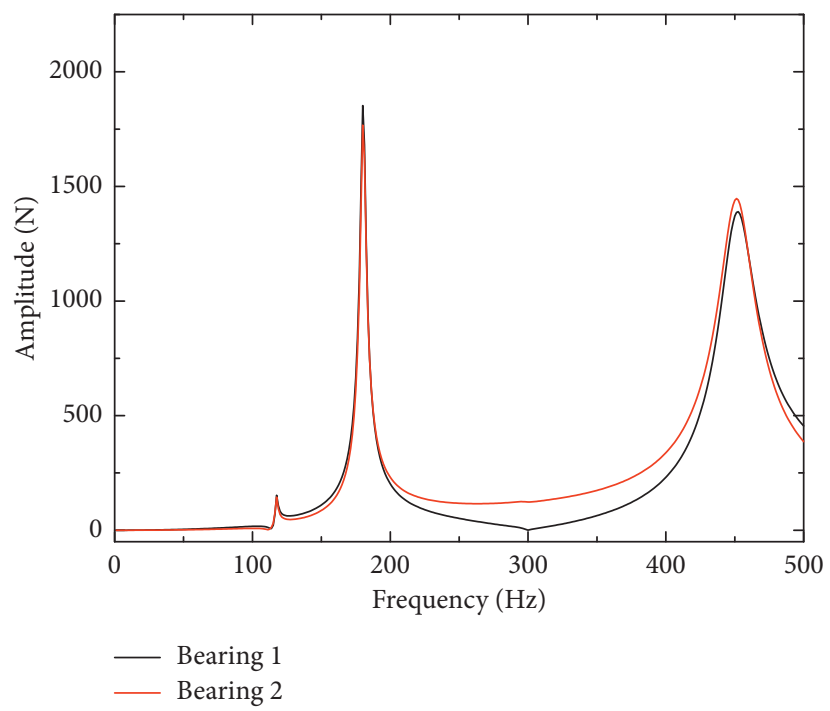

(d)

FIGURE 13: Rotor response and support reaction characteristics for condition 3 (anisotropic bearing stiffness). (a) Amplitude response at node 0. (b) Phase response for vertical direction at nodes 0 and 3. (c) Polar diagram for vertical direction at node 0. (d) Support reaction for bearings 1 and 2 at the vertical direction.

The amplitude response at nodes 0 and 3 at the same direction is consistent in Figure 15(b). The phase characteristics are shown in Figures 15(c)-15(d). The phase range of each critical speed region changes in the range of $180^{\circ}$. Bearing support reaction of bearing 1 is consistent with amplitude response, and bearing support reaction of bearing 1 in the cylindrical whirling critical speed region at the vertical direction is relatively larger in Figure 15(f). Resonance circle at the vertical direction is from big to small, which is consistent with the amplitude response. Two circles are formed with similar radius at the horizontal direction, which are, respectively, A and E in the polar diagram of Figure 15(e).

\section{Dynamic Experiments of ACM Rotor System}

5.1. Experimental System. The experimental system includes high pressure gas source (air compressor), vibration testing and analysis system, bearing and driven gas control system, and ACM, as shown in Figure 16.

High-pressure gas source is made up of a screw-type air compressor, gas tank, dryer, and filter. A screw-type air compressor provides high-pressure air with a maximum pressure of $1.2 \mathrm{MPa}$ and maximum mass flow of $3.90 \mathrm{~kg} / \mathrm{s}$. The volume of the gas tank is $8 \mathrm{~m}^{3}$. Bearing and driven gas control system contains pressure gauge, thermometer, flow meter, 


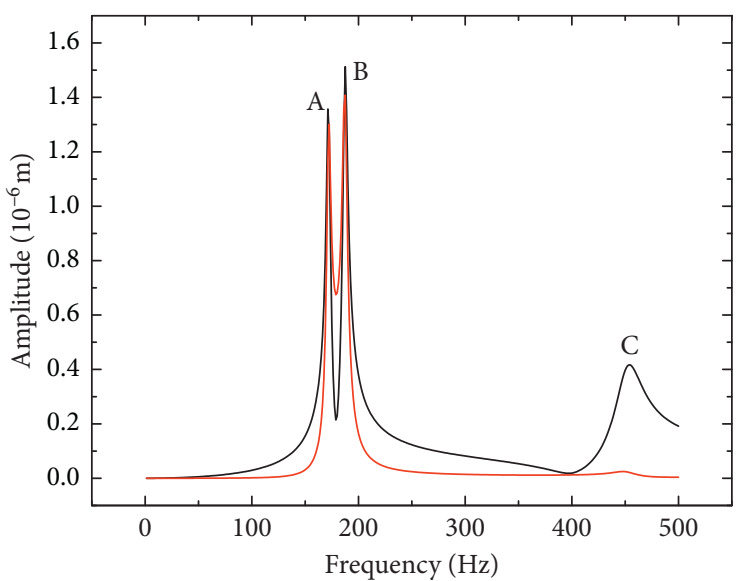

Vertical

Horizontal

(a)

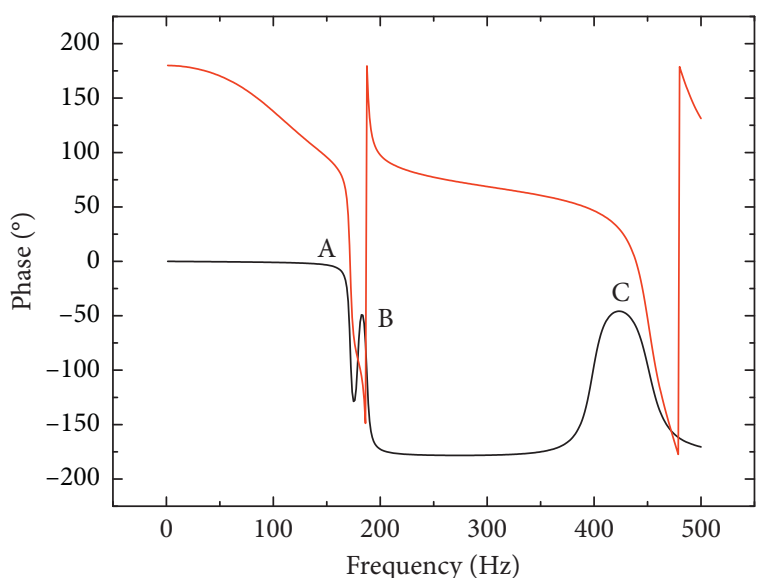

_ Vertical

_ Horizontal

(c)

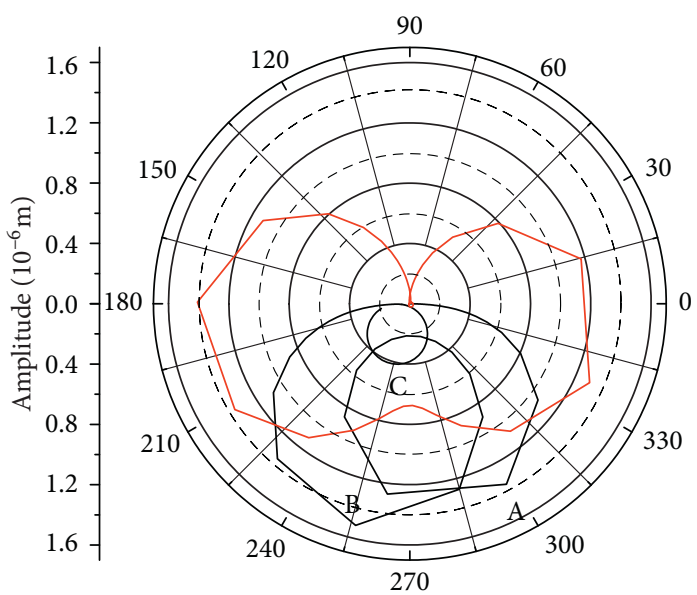

Vertical

Horizontal

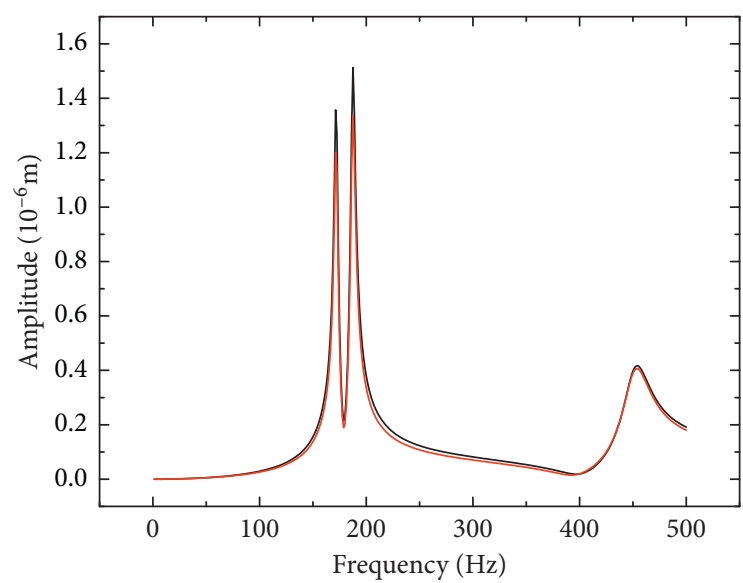

Node 0

Node 3

(b)

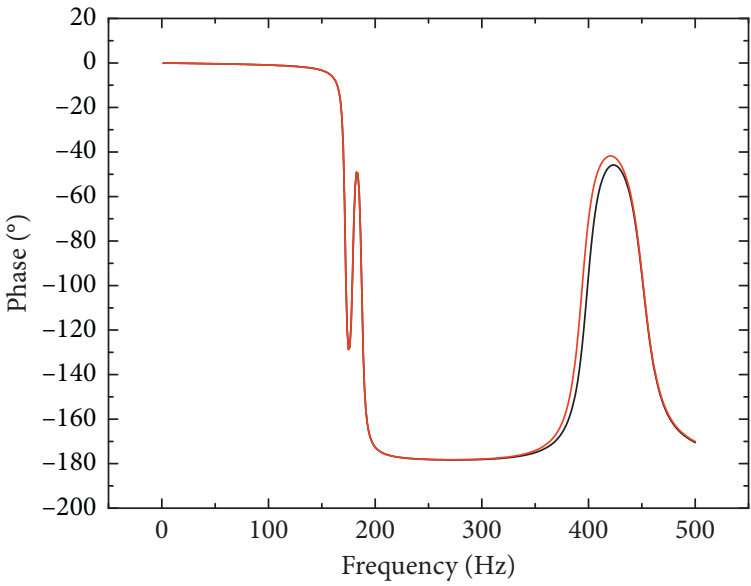

Node 0

Node 3

(d)

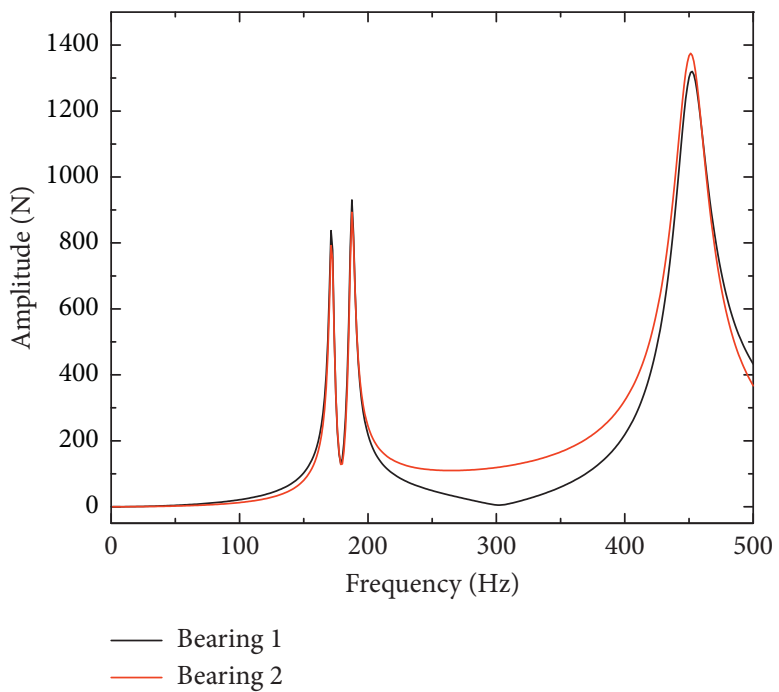

(f)

FIGURE 14: Rotor response and support reaction characteristics for condition 4 (isotropic bearing stiffness). (a) Amplitude response at node 0. (b) Amplitude response for vertical direction. (c) Phase response for at node 0. (d) Phase response for vertical direction. (e) Polar diagram for horizontal direction at node 0. (f) Support reaction at vertical direction. 


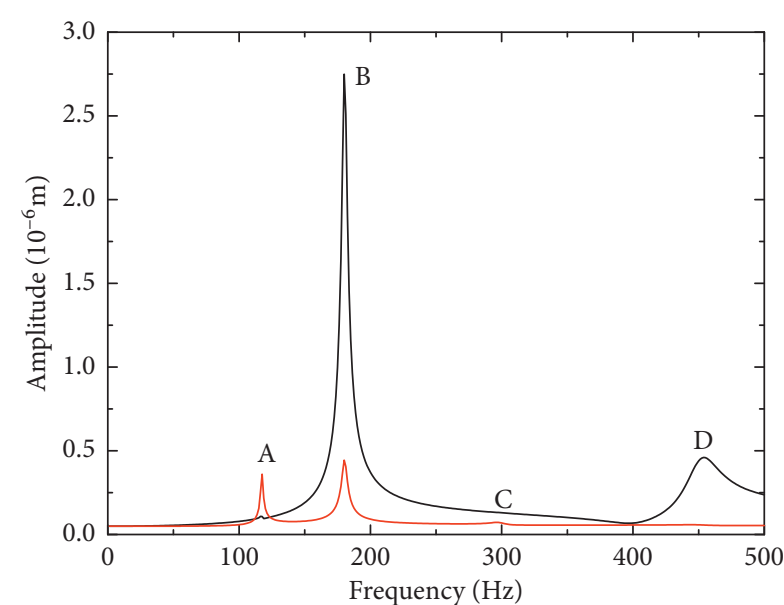

- Vertical

Horizontal

(a)

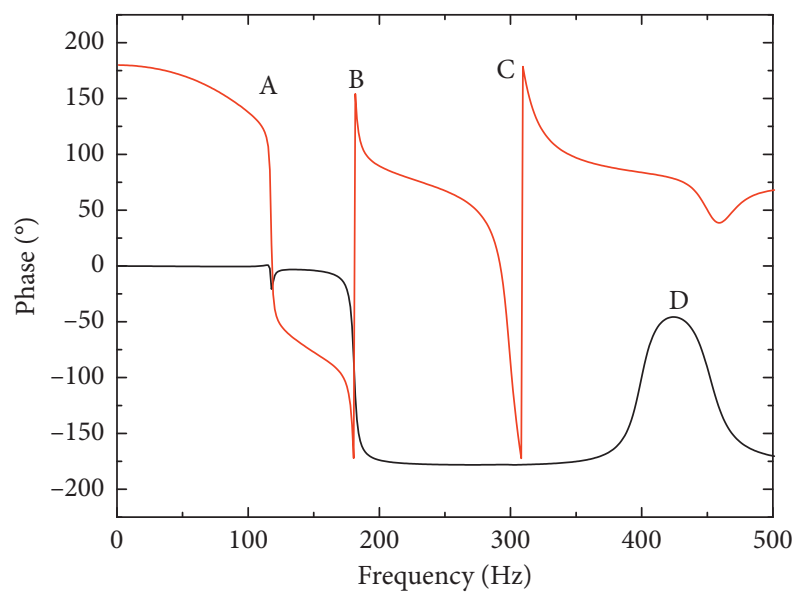

- Vertical

- Horizontal

(c)

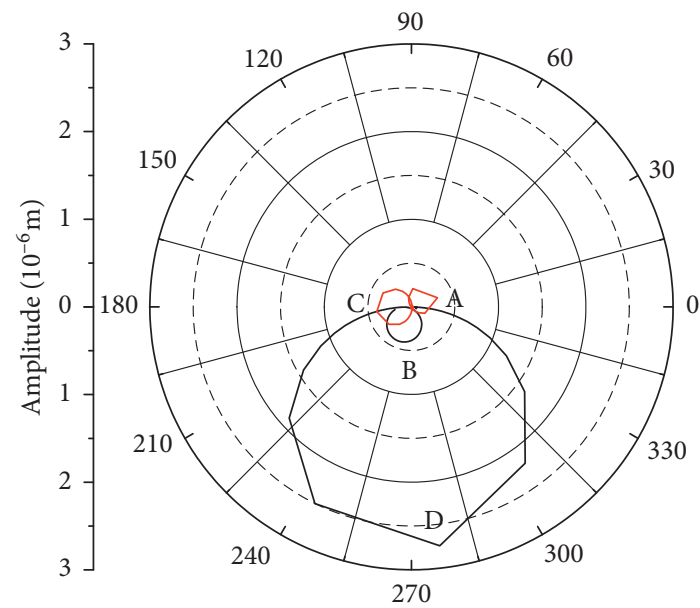

Vertical

- Horizontal

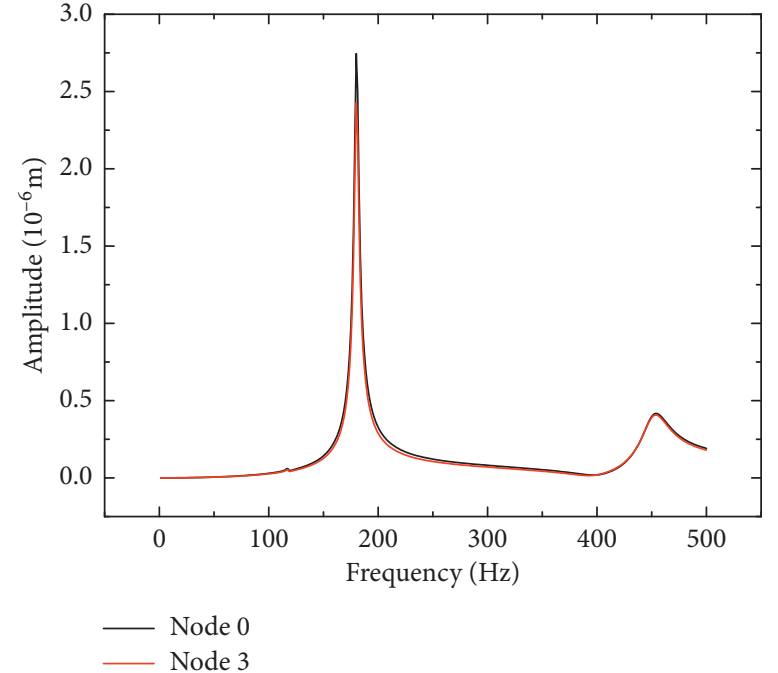

(b)

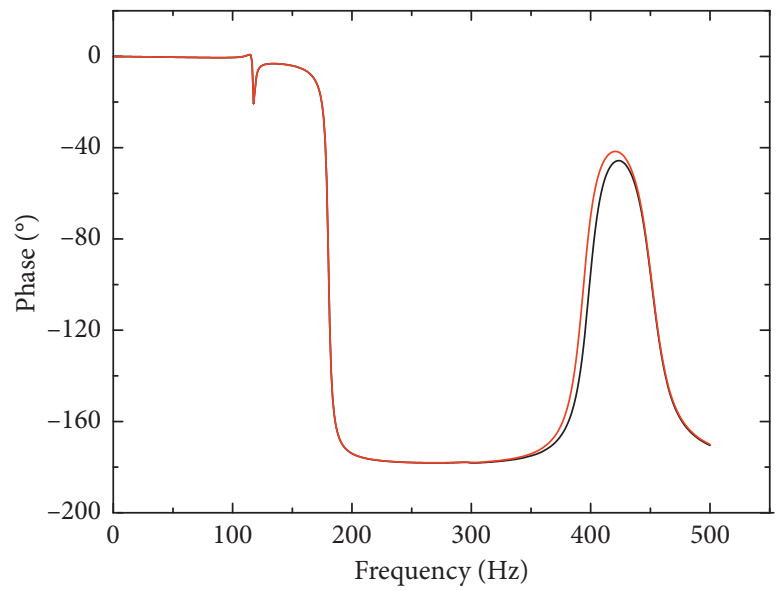

Node 0

Node 3

(d)

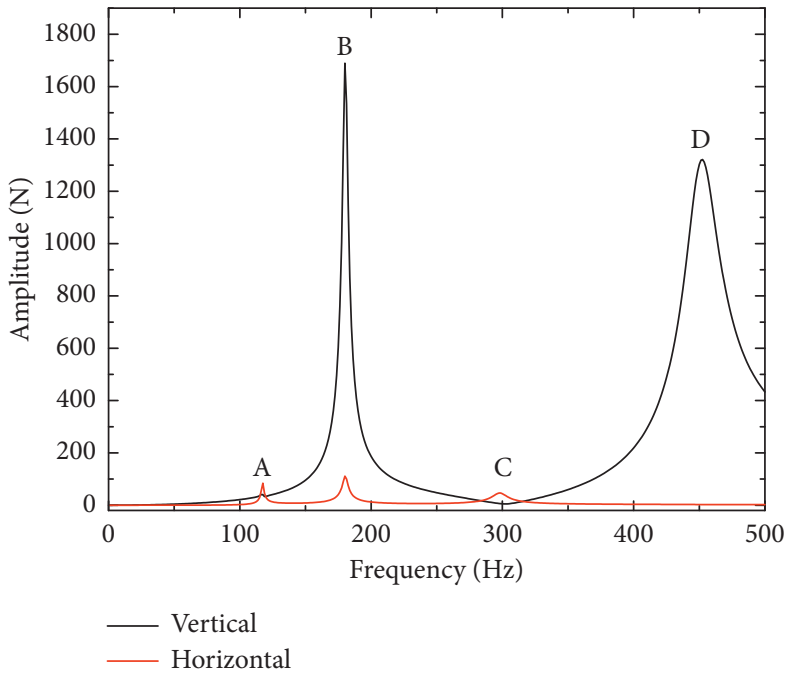

(f)

FIGURE 15: Rotor response and support reaction characteristics for condition 4 (anisotropic bearing stiffness). (a) Amplitude response at node 0. (b) Amplitude response for vertical direction. (c) Phase response at node 0. (d) Phase response for vertical direction. (e) Polar diagram at node 0. (f) Support reaction for bearing 1 at node 0 . 


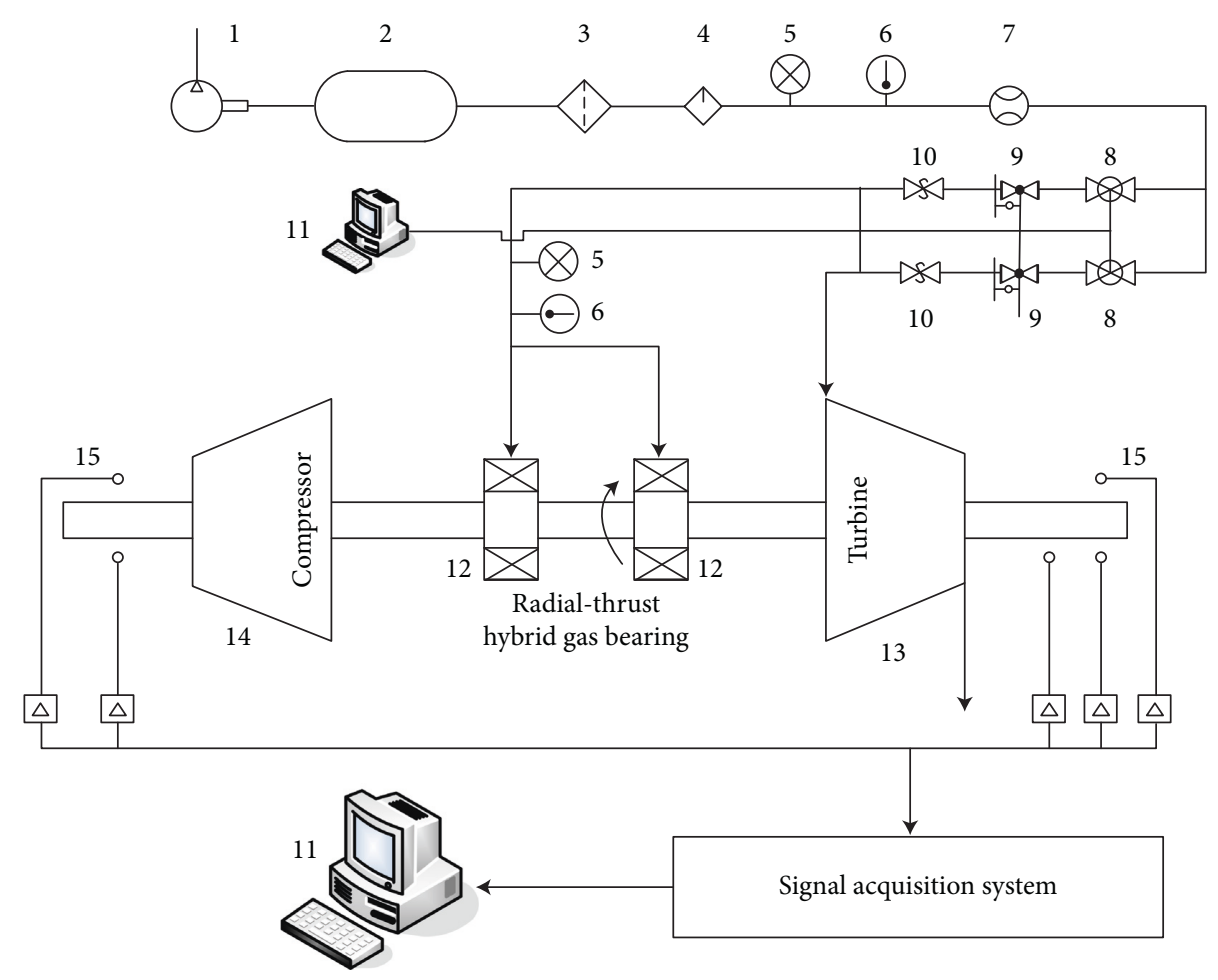

Figure 16: Sketch map for ACM test rig. (1) Air compressor, (2) gas tank, (3) filter, (4) dryer, (5) pressure gauge, (6) thermometer, (7) flow meter, (8) pressure stabilizing valve, (9) electropneumatic air regulator, (10) safety shut-off valves, (11) computer, (12) radial-thrust hybrid gas bearing, (13) turbine, (14) data acquisition, and (15) eddy current displace sensor.

pressure stabilizing valve, electro-pneumatic air regulator, and safety shut-off valve. The gas control system achieves the following functions based on LabVIEW, including speed control, bearing gas pressure control, alert control, and graphical display. Subsection speed control is realized in the acceleration and deceleration process. Different rise rates can be set, and different settling time can be set at the end of acceleration. Subdivision control and automatic control is realized in the bearing gas pressure control, which means different bearing gas pressure can be set during different speed regions. Vibration and overspeed control is achieved in alert control. The control system displays the parameters of pressure, flow, and temperature in real time and completes data online monitoring and offline analysis. The vibration testing and analysis system includes eddy current displace sensors, data acquisition, and computers. Two pairs of eddy current sensors, which are outside the impellers, orthogonally positioned, and facing the rotor ends, are utilized to measure the rotor lateral vibration amplitudes along the $X$-(vertical) and $Y$-(horizontal) planes. Another eddy current sensor mounted at the turbine end of the rotor is used to act as a keyphase signal for data acquisition and processing. The rotor system of ACM has been described in Section 2.

5.2. Critical Speed Characteristic Analysis of ACM. The bearing supply gas pressure is at $0.70 \mathrm{MPa}$ in the experiments. As shown in Figures 17 and 18, Bode diagram and axis center track are used to describe the critical speed characteristics.
In Figure 17(a), resonance separation occurs during the conical whirling critical speed region. The first resonance peak at the turbine end in the vertical direction is at $12,930 \mathrm{r} / \mathrm{min}(66.64 \mu \mathrm{m})$, and the second is at $15,071 \mathrm{r} / \mathrm{min}$ $(36.29 \mu \mathrm{m})$. Two circles are formed at the conical whirling critical speed region In Figure 17(b). The phase range of two circles changes in the range of $180^{\circ}$. Phase difference of the main peak is $180^{\circ}$ between the turbine end and compressor end at the vertical direction, which reflects conical whirling feature. The amplitude of the cylindrical whirling critical speed region is restrained, and there are not obvious resonance peaks at the turbine end in the vertical direction after the conical whirling critical speed. The characteristics of the compressor end at the vertical direction are similar to that of the turbine end at the vertical direction.

There are many small peaks from $21,000 \mathrm{r} / \mathrm{min}$ to $27,000 \mathrm{r} / \mathrm{min}$ after the conical whirling critical speed at the compressor end. Resonance separation also occurs during the conical whirling critical speed region. The first resonance peak at the compressor end in the horizontal direction is at $12,021 \mathrm{r} / \mathrm{min}(33.49 \mu \mathrm{m})$, and the second is at $14,455 \mathrm{r} / \mathrm{min}$ $(41.18 \mu \mathrm{m})$. The critical circle is from small to big, which is contrary to that in the vertical direction. By comparison, the critical speed value during the conical whirling critical speed region is smaller than that in the vertical direction. The conclusions are that bearing stiffness at the compressor in the horizontal direction is smaller than that in the vertical direction. The phase also appears regular fluctuations. The amplitude appears a peak near $24,400 \mathrm{r} / \mathrm{min}$, which is regarded as the second-order critical speed (cylindrical whirling critical speed). 


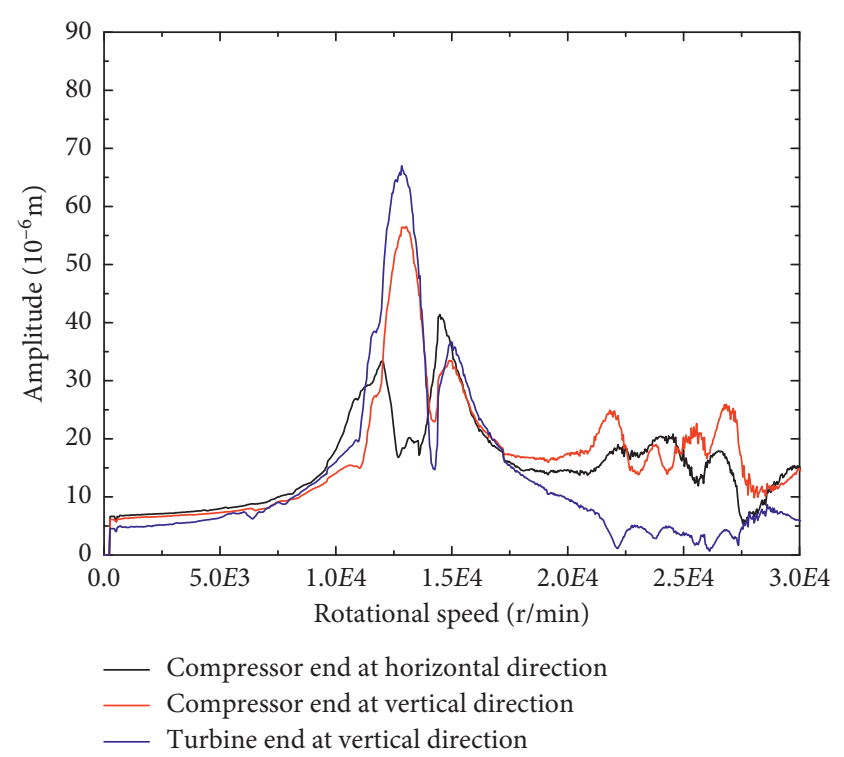

(a)

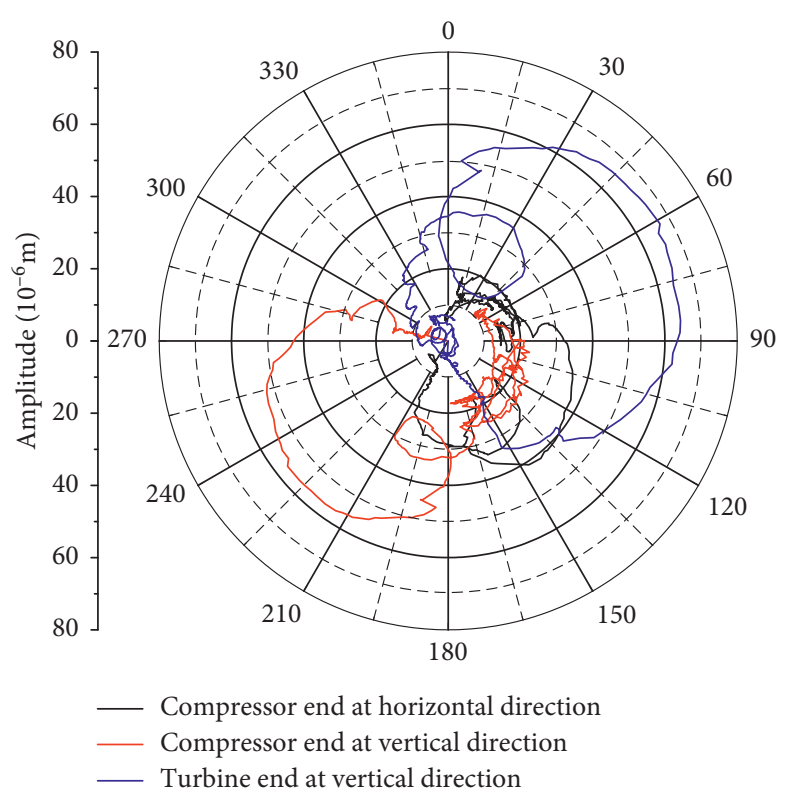

(b)

Figure 17: Bode diagram in the acceleration process. (a) Amplitude response. (b) Bode diagram.

Combined with the results of Section 3, unbalanced exciting force of different amplitudes and different phases on two impellers cause the resonance separation at the horizontal and vertical direction, and restrained amplitude in the cylindrical whirling critical speed region. Bearing stiffness anisotropy brings vibration amplitude of critical speed different.

Axis center tracks for the compressor end in the conical whirling critical speed region are shown in Figure 18. Taking $\mathrm{A}$ as the initial state, axis center track displays ellipse $\mathrm{A}$ at this moment, and long axis of A points to $160^{\circ}$. When axis center track changes from $\mathrm{A}$ to $\mathrm{B}$, the amplitude at the vertical direction is larger, and resonance peak of the conical whirling critical speed region is just here. With the increase in speed, minor axis gets shorter, and axis center track turns C. The axis center track of the second resonance peak is D at $14,320 \mathrm{r} / \mathrm{min}$. The axis center track turns into approximate round $\mathrm{E}$ at $17,134 \mathrm{r} / \mathrm{min}$ after the conical whirling critical speed region. The phase of long axis turns from $160^{\circ}$ to $30^{\circ}$, with axis center tracks from $\mathrm{A}$ to $\mathrm{E}$.

\section{Conclusions}

Numerical simulation and experimental verification are used to research effects of unbalanced exciting force on ACM rotor response and bearing support reaction. The main conclusions are as follows.

The front two-order critical speed for the rotor system of ACM is, respectively, conical whirling and cylindrical whirling critical speed, which reflects elastic characteristics of the gas film. The critical speed values increase with gas film stiffness. The amplitude of critical speed is related to gas film and unbalanced exciting force characteristics. When bearing stiffness is anisotropic, the front two-order critical

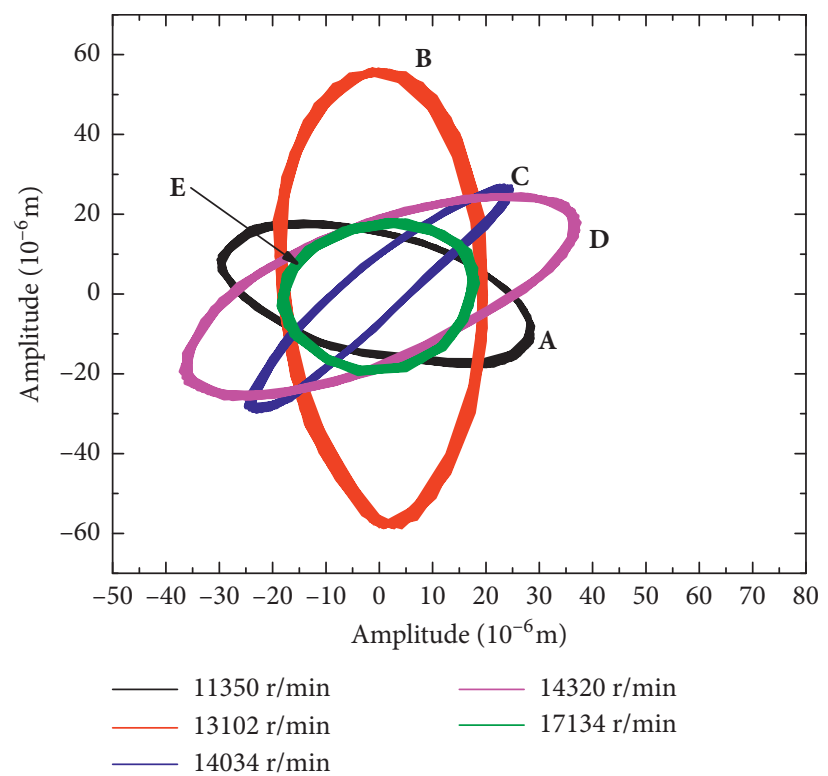

Figure 18: Axis orbits at five moments during the conical whirling critical speed region.

speed appears with differences between the horizontal direction and vertical direction. The horizontal bearing stiffness is smaller than the vertical bearing stiffness, and the critical speed value at the horizontal direction is smaller than the value at the vertical direction.

The resonance separation phenomenon appears in the conical whirling speed region when difference exists in the phase of applied unbalanced exciting force. The resonance separation phenomenon also occurs when the amplitude of unbalanced exciting force is different and meanwhile, bearing stiffness is anisotropic. When unbalanced exciting 
force applied on the impellers has the same phase, the amplitude in the cylindrical whirling critical speed will be enlarged. In the dynamic experiments of the ACM rotor system, the resonance separation phenomenon in the conical whirling speed region is verified.

The reasons for the resonance separation characteristics of the ACM rotor system are given combined with numerical simulation results, which could provide references for the parameters selection and optimization of the critical speed region, and also could provide theoretical support for the corresponding vibration fault diagnosis.

\section{Data Availability}

The data used to support the findings of this study are included within the article.

\section{Conflicts of Interest}

The authors declare that they have no conflicts of interest.

\section{Acknowledgments}

This work was supported by the National Natural Science Foundation (Grant No. 11602268), and the support is gratefully acknowledged.

\section{References}

[1] J. Z. Yu, Y. J. Qian, and Z. Gao, "Advanced technology in the design of environmental control system for avionics pods," Journal of Beijing University of Aeronautics and Astronautics, vol. 24, no. 2, pp. 212-215, 1998.

[2] Z. Y. Qin, Q. K. Han, and F. L. Chu, "Analytical model of bolted disk-drum joints and its application to dynamic analysis of jointed rotor," Proceedings of the Institution of Mechanical Engineers, Part C: Journal of Mechanical Engineering Science, vol. 228, no. 4, pp. 646-663, 2014.

[3] X. J. Xiao and X. G. Yuan, "Research on motor-driven reverse bootstrap air cycle refrigerating system used on aircraft pod," Journal of Beijing University of Aeronautics and Astronautics, vol. 31, no. 11, pp. 1163-1167, 2005.

[4] B. Xiao, "Environmental control system for airborne pods," Electro-Mechanical Engineering, vol. 24, no. 3, pp. 14-16, 2008.

[5] J. Z. Yu and N. Su, "Design and parameter optimization for environmental control system of aircraft avionics pods," Journal of Astronautics, vol. 21, no. 5, pp. 399-404, 2000.

[6] H. Heshmat and P. Hermel, "Compliant foil bearing technology and their application to high speed turbomachinery," The 19th Leeds-Lyon Symposium on Thin Film in TribologyFrom Micro Meters to Nano Meters, Elsevier, Leeds, UK, pp. 559-575, 1992.

[7] H. Heshmat, "Role of compliant foil bearings in advancement and development of high-speed turbomachinery," Fluid Engineering Conference of Second ASME Pumping Machinery Symposium, vol. 154, pp. 359-377, 1993.

[8] A. Hunsberger, J. F. Walton, and H. Heshmat, "Debris tolerant compliant foil bearings for high-speed turbomachines," in Proceedings of ASME Turbo ExpoTurbine Technical Conference and Exposition, Washington, DC, USA, June 2015.

[9] X. J. Xiao, X. G. Yuan, S. L. Zhang et al., "Experimental investigation of turbine-compressor unit driven by high-speed electric motor," Vacuum \& Cryogenics, vol. 14, no. 4, pp. 208-211, 2008.

[10] Y. Hou, H. L. Zhao, and C. Z. Chen, "Durability and stability analysis of compliant foil journal bearings with elastic support using different surface treatments," Tribology Transactions, vol. 51, no. 2, pp. 187-192, 2008.

[11] C. A. Heshmat, D. S. Xu, and H. Heshmat, "Analysis of gas lubricated foil thrust bearings using coupled finite element and finite difference methods," Journal of Tribology, vol. 122, no. 1, pp. 199-204, 1999.

[12] C. Chen, J. F. Yang, and J. W. Lou, "Experimental study on nonlinear dynamics characteristics of high-speed rotor-gas lubrication bearing system," in Proceedings of ASME Turbo Expo 2008: Power for Land, Sea, and Air, pp. 941-946, American Society of Mechanical Engineers, Berlin, Germany, June 2008.

[13] D. Han, J. Yang, C. Chen et al., "Experimental research on dynamic characteristics of gas-hybrid bearing-flexible rotor system," Journal of Vibroengineering, vol. 16, no. 5, pp. 2363-2374, 2014.

[14] S. Morosi and I. F. Santos, "On the modeling of hybrid aerostatic-gas journal bearings," Proceedings of the Institution of Mechanical Engineers, Part J: Journal of Engineering Tribology, vol. 225, no. 7, pp. 641-653, 2011.

[15] S. A. Luis and K. Ryu, "Hybrid gas bearings with controlled supply pressure to eliminate rotor vibrations while crossing system critical speeds," Journal of Engineering for Gas Turbines and Power, vol. 130, no. 6, article 062505, 2008.

[16] K. Czołczyński and K. Marynowski, "Stability of symmetrical rotor supported in flexibly mounted, self-acting gas journal bearings," Wear, vol. 194, no. 1-2, pp. 190-197, 1996. 


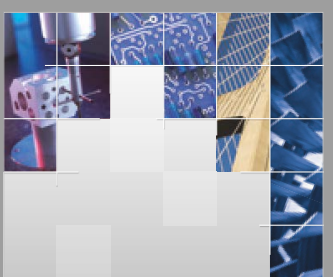

\section{Enfincering}
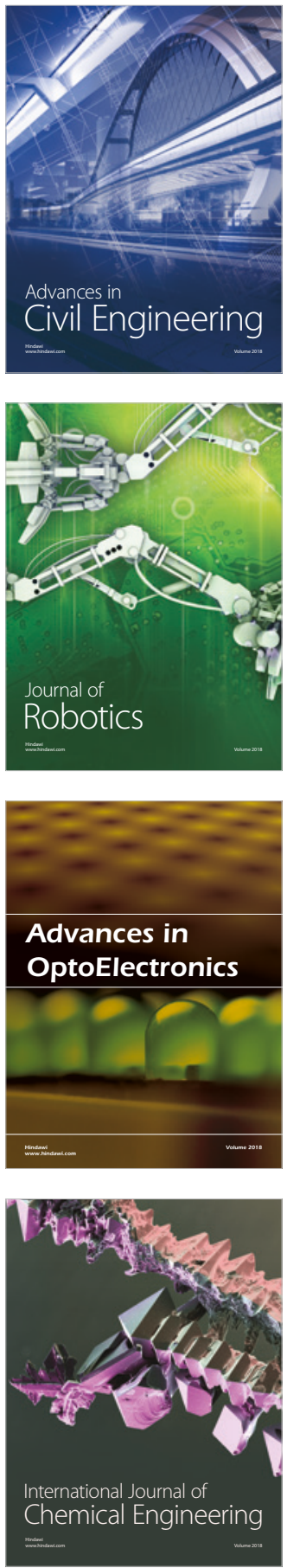

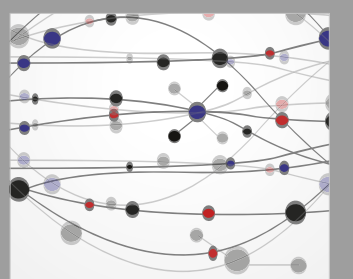

\section{Rotating \\ Machinery}

The Scientific World Journal

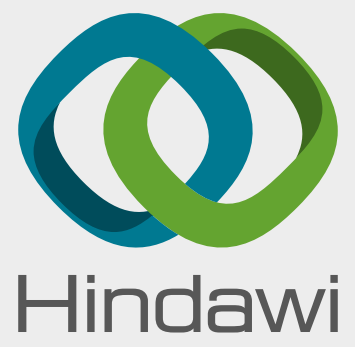

Submit your manuscripts at

www.hindawi.com
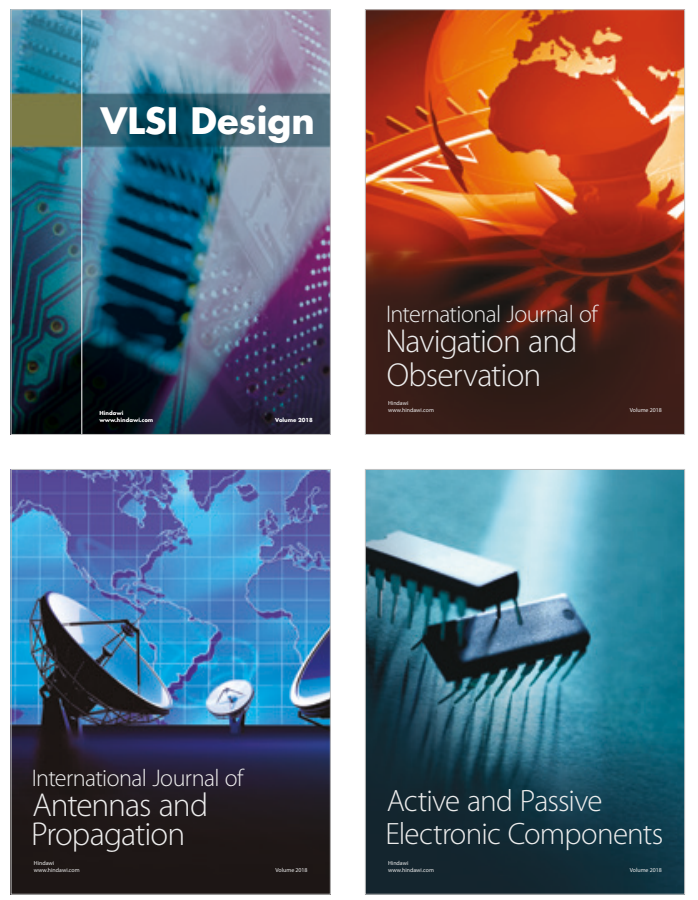
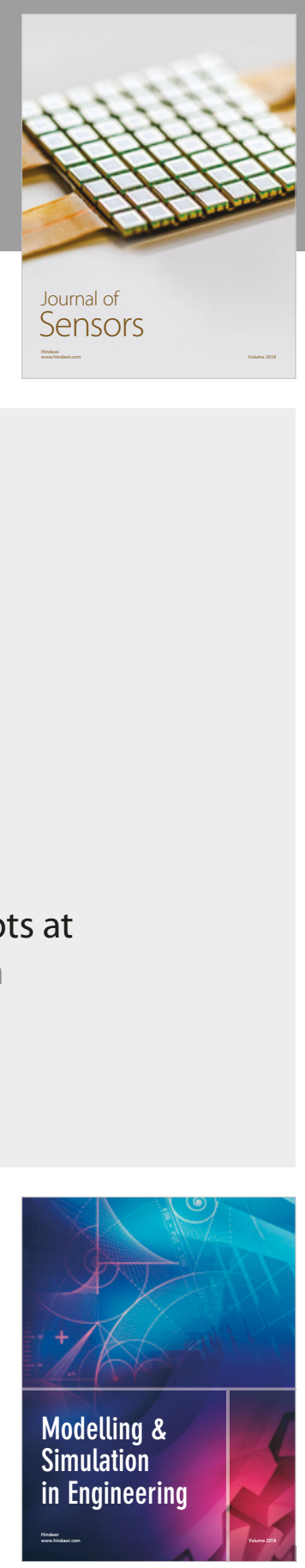

\section{Advances \\ Multimedia}
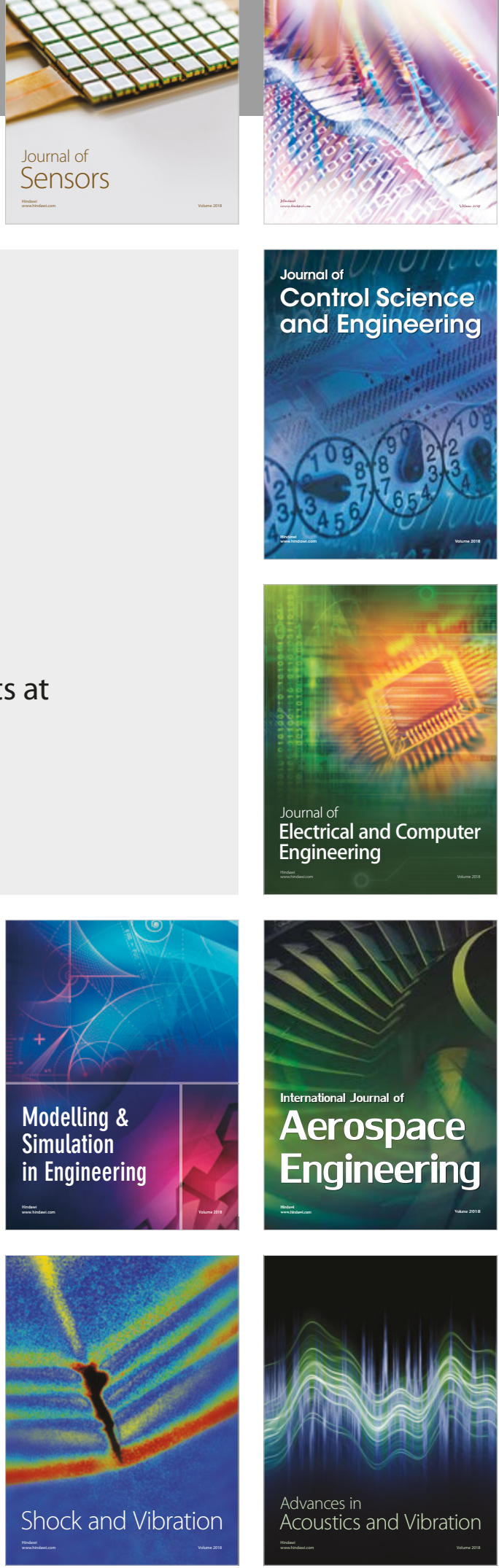